\title{
GNREL
}

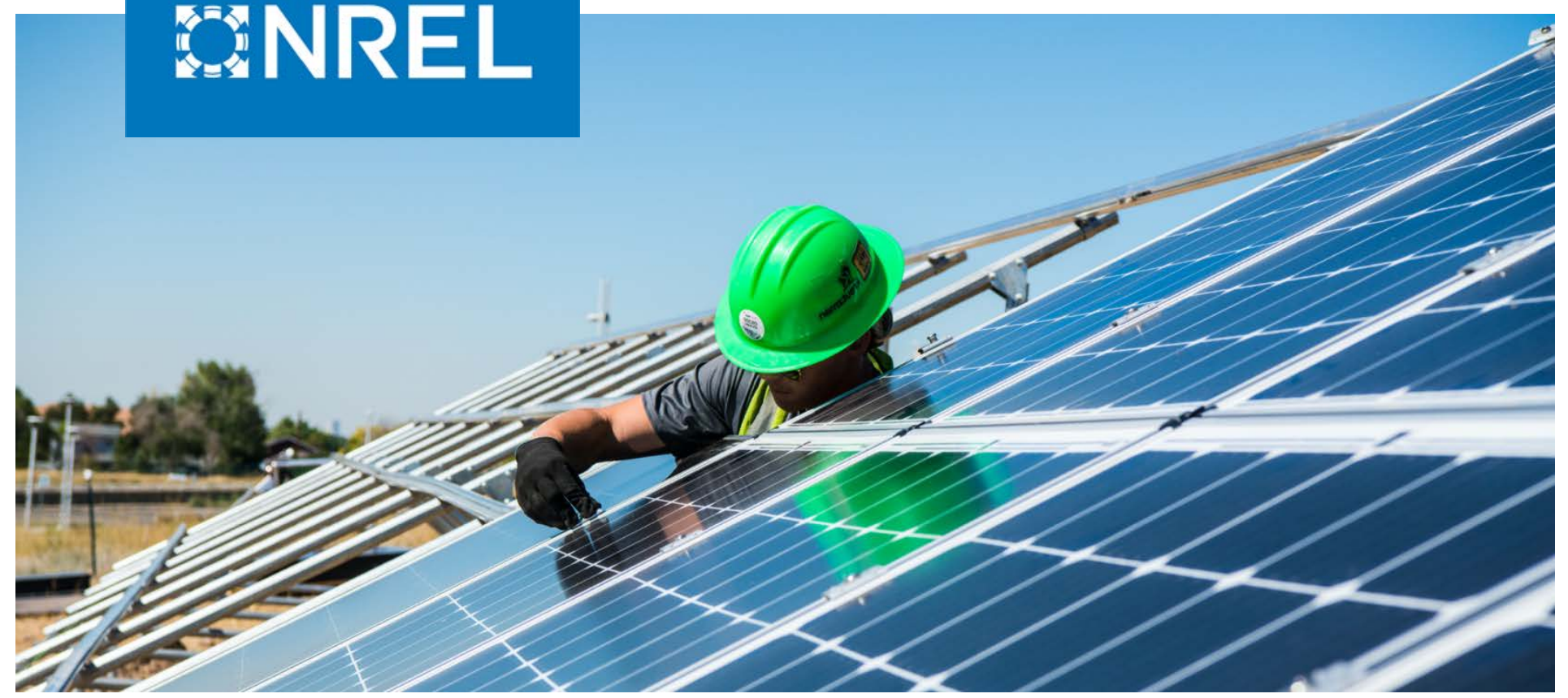

\section{The Demand-Side Opportunity: The Roles of Distributed Solar and Building Energy Systems in a Decarbonized Grid}

Eric O'Shaughnessy ${ }^{1}$ and Monisha Shah ${ }^{2}$

${ }^{1}$ Clean Kilowatts, LLC

${ }^{2}$ National Renewable Energy Laboratory

NREL is a national laboratory of the U.S. Department of Energy Office of Energy Efficiency \& Renewable Energy

Operated by the Alliance for Sustainable Energy, LLC

This report is available at no cost from the National Renewable Energy Laboratory (NREL) at www.nrel.gov/publications.
Technical Report

NREL/TP-6A20-80527

September 2021 


\title{
FAREL
}

\section{The Demand-Side Opportunity: The} Roles of Distributed Solar and Building Energy Systems in a Decarbonized Grid

\author{
Eric O'Shaughnessy ${ }^{1}$ and Monisha Shah ${ }^{2}$ \\ ${ }^{1}$ Clean Kilowatts, LLC \\ ${ }^{2}$ National Renewable Energy Laboratory
}

\section{Suggested Citation}

O'Shaughnessy, and Monisha Shah. 2021. The Demand-Side Opportunity: The Roles of Distributed Solar and Building Energy Systems in a Decarbonized Grid. Golden, CO: National Renewable Energy Laboratory. NREL/TP-6A20-80527.

https://www.nrel.gov/docs/fy210sti/80527.pdf.

NREL is a national laboratory of the U.S. Department of Energy Office of Energy Efficiency \& Renewable Energy Operated by the Alliance for Sustainable Energy, LLC

This report is available at no cost from the National Renewable Energy Laboratory (NREL) at www.nrel.gov/publications.

Contract No. DE-AC36-08GO28308
Technical Report

NREL/TP-6A20-80527

September 2021

National Renewable Energy Laboratory 15013 Denver West Parkway Golden, CO 80401 303-275-3000 • www.nrel.gov 


\section{NOTICE}

This work was authored by the National Renewable Energy Laboratory, operated by Alliance for Sustainable Energy, LLC, for the U.S. Department of Energy (DOE) under Contract No. DE-AC36-08GO28308. Funding provided by U.S. Department of Energy Office of Energy Efficiency and Renewable Energy Solar Energy Technologies Office. The views expressed herein do not necessarily represent the views of the DOE or the U.S. Government.

This report is available at no cost from the National Renewable Energy Laboratory (NREL) at www.nrel.gov/publications.

U.S. Department of Energy (DOE) reports produced after 1991 and a growing number of pre-1991 documents are available free via www.OSTI.gov.

Cover Photo by Dennis Schroeder: NREL 40820.

NREL prints on paper that contains recycled content. 


\section{The Solar Futures Study and Supporting Reports}

The Solar Futures Study, initiated by the U.S. Department of Energy (DOE) Solar Energy Technologies Office and led by the National Renewable Energy Laboratory (NREL), envisions how, over the next few decades, solar could come to power $40 \%$ or more of U.S. electricity demand, dramatically accelerating the decarbonization of buildings, transportation, and industry.

Through state-of-the-art modeling, the Solar Futures Study is the most comprehensive review to date of the potential role of solar in decarbonizing the U.S. electric grid and broader energy system. However, not all the detailed analysis that informed the Solar Futures Study could be included within its pages. This further analysis is collected in additional National Renewable Energy Laboratory reports, each dedicated to a different technology or socioeconomic concern.

This report, The Demand-Side Opportunity: The Roles of Distributed Solar and Building Energy Systems in a Decarbonized Grid, focuses on a particular sector that could contribute to decarbonization.

\section{The Solar Futures Study Reports}

- Solar Futures Study (main report published by DOE)

- Research Priorities for Solar Photovoltaics in a Decarbonized U.S. Grid

- The Role of Concentrating Solar-Thermal Power Technologies in a Decarbonized U.S. Grid

- $\quad$ The Demand-Side Opportunity: The Roles of Distributed Solar and Building Energy Systems in a Decarbonized Grid

- Maximizing Solar and Transportation Synergies

- $\quad$ The Potential for Electrons to Molecules Using Solar Energy

- Affordable and Accessible Solar for All: Barriers, Solutions, and On-Site Adoption Potential

- Forthcoming Environment and Circular Economy Report

You can learn more about the project and reports on the NREL website at https://www.nrel.gov/analysis/solar-futures.html.

In this report, we cite the Solar Futures Study and other complementary technical reports as additional sources of information. When referring to modeling results from the Solar Futures Study, we use results from the Decarbonization Plus Electrification (Decarb+E) scenario, representing the most aggressive scenario in terms of renewable energy cost reductions and projections for electrification. See the Solar Futures Study for additional details on the scenarios. 


\section{Acknowledgments}

This work was supported by the Solar Energy Technologies Office at the U.S. Department of Energy. The authors would like to thank the following individuals and organizations for their participation in a technical review panel for this report: Mark Dyson (Rocky Mountain Institute), Alexi Miller (New Buildings Institute), David Parra (University of Geneva), Mike Roberts (UNSW Sydney), and Reuven Sussman (American Council for an Energy Efficient Economy). The authors would also like to thank Deanna Cook, Harrison Dreves, and Susannah Shoemaker for editorial support; Dylan Cutler, Hallie Dunham, Ted Kwasnik, Sakshi Mishra, Ben Polly, Ashok Sekar, and Ben Sigrin (NREL) for modeling support; and Sara Dong (NREL) for research support. 


\section{Executive Summary}

Buildings house numerous energy technologies that can be used as demand-side grid resources, such as energy-efficient devices, flexible loads, and energy storage. Leveraging building energy technologies to provide demand-side grid services can engage electricity customers in the clean energy transition, reduce grid emissions, and provide valuable grid services. These technologies can also enable the deployment of distributed solar photovoltaics (DPV) by reshaping building load profiles to optimize DPV use. DPV optimization can drive DPV adoption and make DPV more valuable to the grid. On their own, demand-side resources are insufficient for deep decarbonization, and they entail important tradeoffs relative to large-scale assets, particularly in terms of foregone economies of scale and the uncertainties of end user behavior. Nonetheless, demand-side resources will play a key role in deep decarbonization for several reasons, including their unique locational benefits, their ability to use underutilized building spaces, their nonenergy benefits (e.g., local resiliency), and their ability to help achieve energy justice objectives and ensure a more equitable distribution of the benefits of grid transformation.

In this report, we explore the role of demand-side resources in grid transformation and deep decarbonization. Through a literature review supplemented with National Renewable Energy Laboratory (NREL) modeling, we reach the following conclusions.

\section{Demand-side resources are underutilized.}

DPV, building energy technologies, and building energy automation systems are broadly available but underutilized. More than $95 \%$ of DPV-viable rooftop space remains unused. Only about a quarter of flexible load is enrolled in demand-side service programs, and even those services are rarely provided.

\section{Underutilized demand-side resources present an opportunity to decarbonize grids more} quickly and cost-effectively.

Demand-side resources can complement centralized supply-side approaches to deep decarbonization. Demand-side resources "lower the bar" for decarbonization by reducing net load (i.e., by factoring out DPV from overall demand). By lowering the bar, demand-side resources allow grids to decarbonize with fewer centralized resources. Further, demand-side resources can supplement supply flexibility with demand flexibility, which can significantly reduce deep decarbonization costs. Available literature and NREL modeling suggest that demand-side resources could collectively drive about $20 \%$ of deep grid decarbonization by providing zero-carbon generation, reducing or shifting buildings loads, and reducing the costs of centralized decarbonization approaches (Figure ES-1). Savings from demand-side measuresparticularly energy efficiency — are already in the hundreds of billions of dollars. Leveraging existing but underutilized demand-side resources could significantly reduce grid operational costs in the near term, and capital costs in the long term, while avoiding hundreds of millions of tons in emissions. 


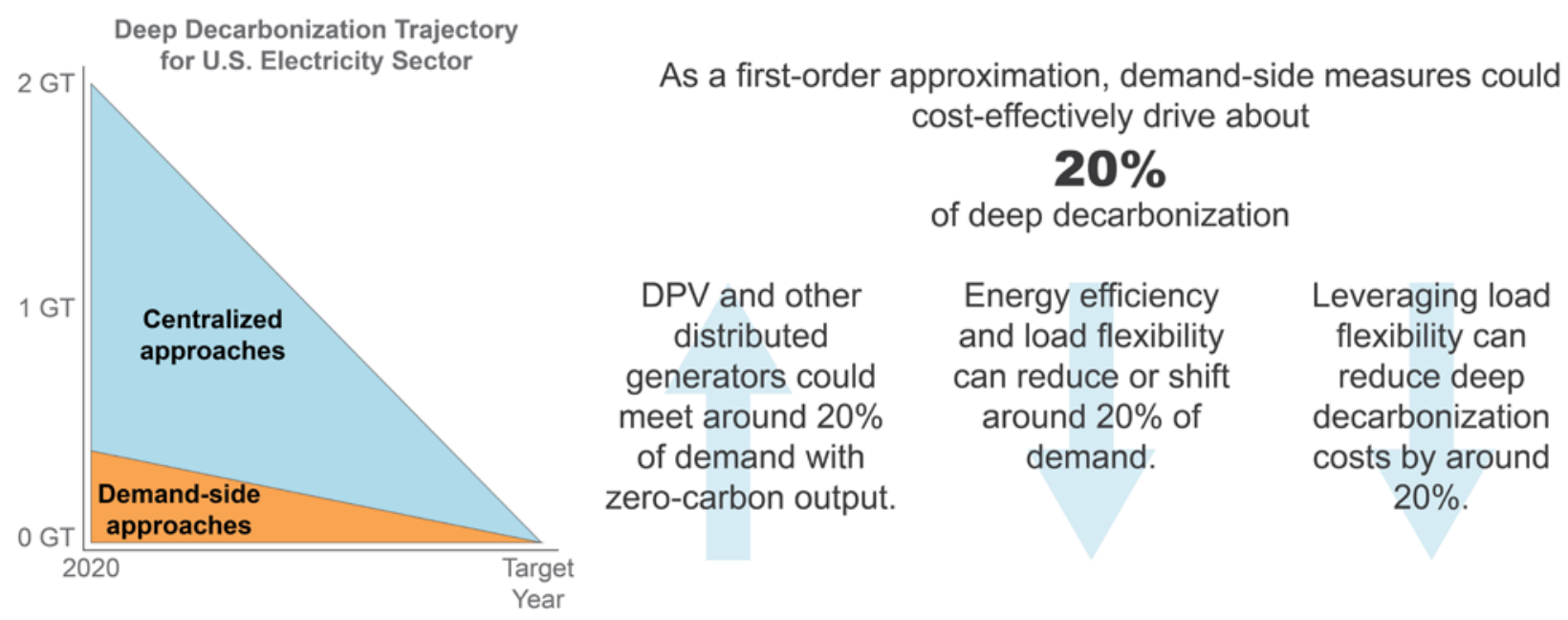

Figure ES-1.The demand-side opportunity

Several solvable challenges pose barriers to the demand-side opportunity.

The underutilization of demand-side resources reflects several barriers, including technological constraints, rate structures that do not incentivize the operation of demand-side resources to provide grid services, regulated utility business models that discourage demand-side services, customer engagement challenges, inequitable technology adoption patterns, and limited access to wholesale markets.

Recent technological, market, and policy trends are eroding the barriers to the demandside opportunity.

Demand-side resource costs have declined, particularly in the cases of DPV and batteries. Advancements in information and communication technology have improved building energy technology automation and coordination capabilities, and effectively coordinated technologies can enable higher DPV penetration levels. For instance, flexible load coordination can maximize the on-site use of DPV, increasing the value proposition of DPV adoption. Enhanced communication capabilities also translate to more effective aggregation, wherein hundreds or thousands of demand-side resources are collectively leveraged to provide grid services. Technological advances could also yield building energy system orchestration, wherein multiple building energy systems are co-optimized for grid services. Emerging business models are finding more ways to effectively leverage underutilized demand-side resources to provide more valuable and reliable demand-side services. Finally, recent regulatory reforms have facilitated demand-side service provision in utility programs and wholesale markets.

\section{Policymakers could explore ways to remove barriers to the beneficial adoption and implementation of demand-side resources and services.}

Several opportunities exist to maximize the realization of the demand-side opportunity, including rate reforms, utility business model reforms, wholesale market reforms, building energy codes, and interventions to optimize building occupant behavior. Policy reforms could incentivize the beneficial adoption of demand-side resources as well as the beneficial use of those resources to provide demand-side services, ensuring that demand-side resources play a key role in transforming and decarbonizing the electric grid. 


\section{Table of Contents}

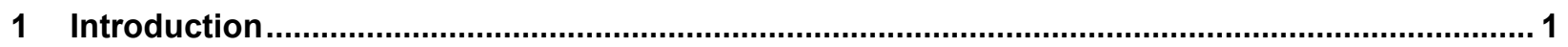

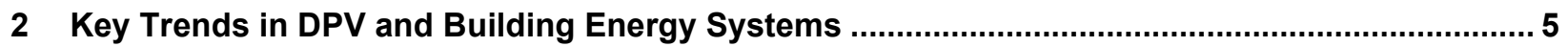

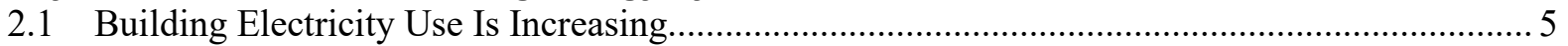

2.2 DPV and Building Energy Technologies Are Proliferating ..................................................... 6

2.3 ICT Advancements Have Facilitated Technology Automation, Coordination, and Aggregation. 6

2.4 Emerging Business Models Have Yielded More Reliable and Valuable Demand-Side Services 9

2.5 Regulatory Reforms Have Mitigated Some Barriers to Demand-Side Services ....................... 10

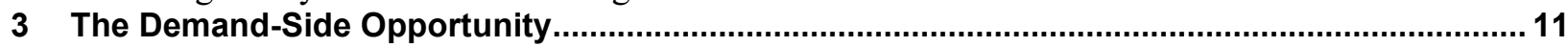

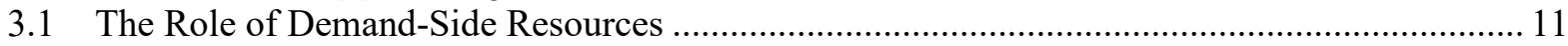

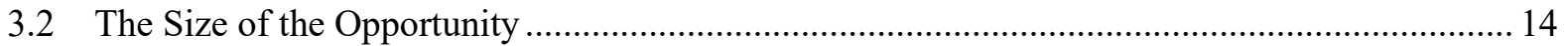

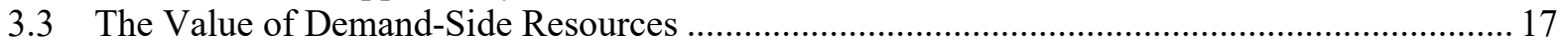

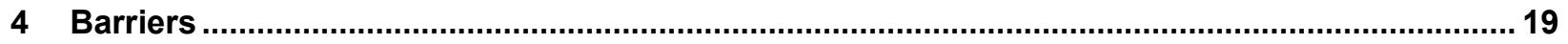

4.1 Barriers to Beneficial Adoption of Demand-Side Resources................................................... 19

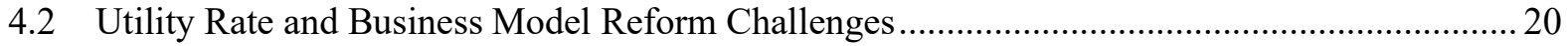

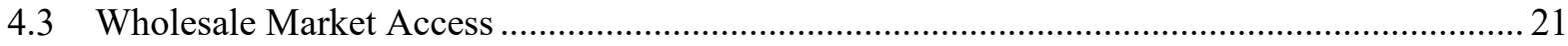

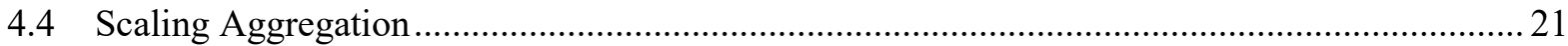

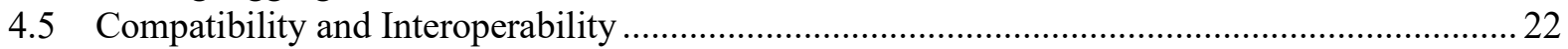

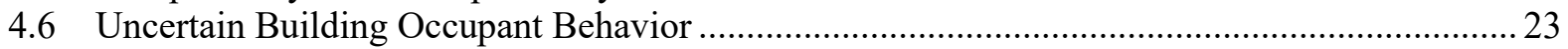

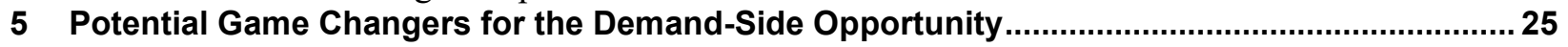

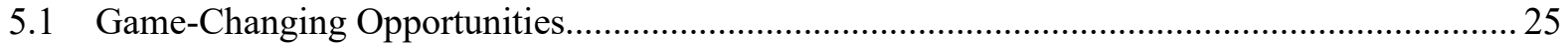

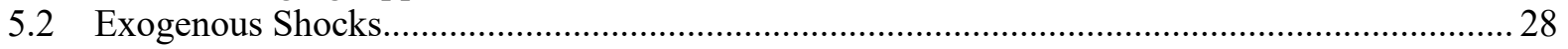

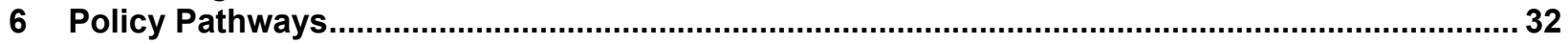

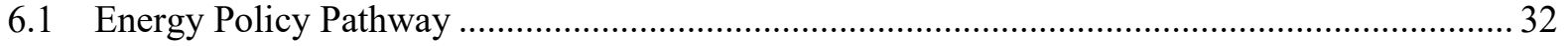

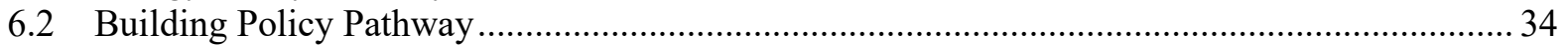

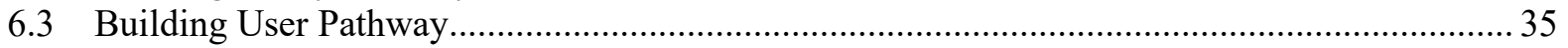

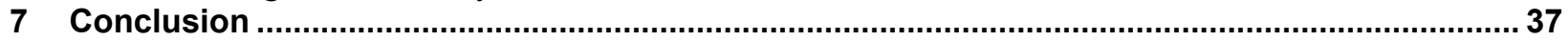

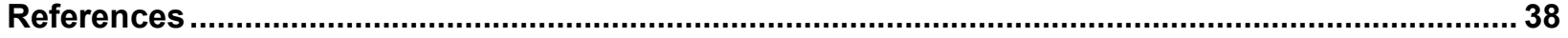

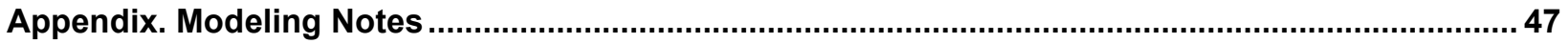




\section{List of Figures}

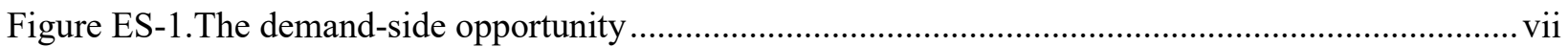

Figure 1. Synergistic functions of DPV and building energy technologies ............................................ 1

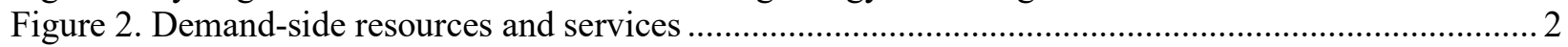

Figure 3. U.S. building square footage (left) and electricity use (right) from 1979 to 2018, based on data

from the U.S. EIA's residential and commercial building energy surveys ............................ 5

Figure 4. Building energy technology automation, coordination, and aggregation .................................. 7

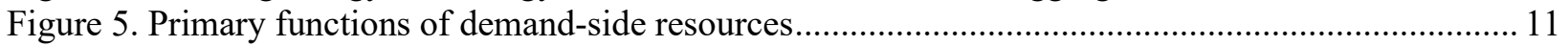

Figure 6. The effect of on-site renewables on grid carbon impact (left) and building contributions to peak

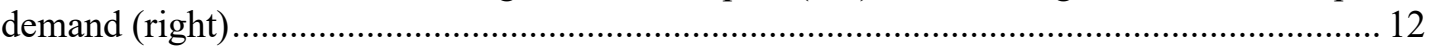

Figure 7. A first-order approximation of the demand-side opportunity ............................................... 14

Figure 8. DPV deployment projections under three rate structure scenarios........................................ 15

Figure 9. Dimensions of building energy device compatibility and interoperability issues ..................... 23

Figure 10. Schematic illustration of building energy system orchestration............................................26

Figure 11. Modeled building energy system orchestration results for optimal DPV system size (left),

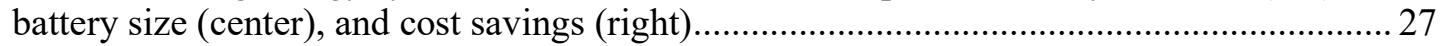

\section{List of Text Boxes}

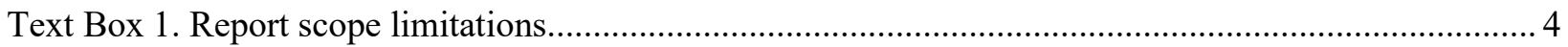

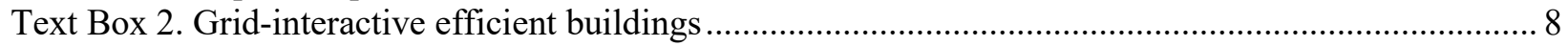

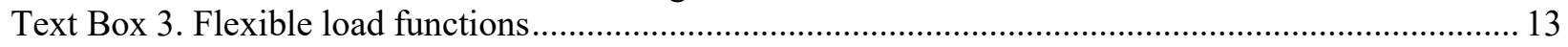

Text Box 4. Grid cost savings using building energy systems as a grid resource …................................ 17

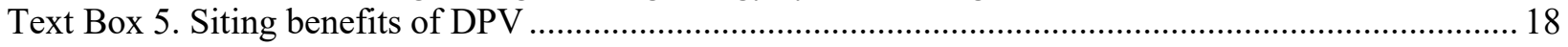

Text Box 6. Demand-side services under conventional utility business models ..................................... 21

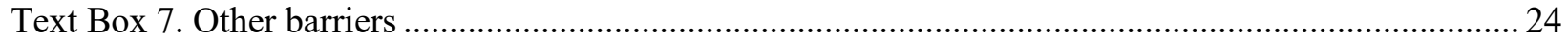




\section{Introduction}

Building energy systems represent a significant and largely untapped demand-side grid resource (Neukomm, Nubbe et al. 2019, Kellison, Kolo et al. 2020, Satchwell, Piette et al. 2021). ${ }^{1}$ Buildings use about $75 \%$ of electricity in the United States, including around $80 \%$ of peak demand, meaning that changes in building energy use have significant implications for grid operations (Fallahi and Henze 2019). Building energy technologies_including energy-efficient devices, flexible loads, and energy storage — can be coordinated and aggregated to perform similar functions as centralized grid assets. Recent advances in information and communication (ICT) technologies have significantly improved building energy technology automation, coordination, and aggregation capabilities (Sofos, Langevin et al. 2020). With declining costs and technological advances, building energy systems can increasingly compete with conventional grid assets such as natural gas plants (Teplin, Dyson et al. 2019).

Building energy technologies enable the deployment of distributed solar photovoltaics (DPV) (Fares and Webber 2017, O'Shaughnessy, Cutler et al. 2018). Energy-efficient buildings allow DPV to meet greater shares of building load, while flexible loads and energy storage can reshape building load profiles to optimize the on-site use of DPV (Figure 1). Optimized on-site use of DPV increases the value proposition for DPV adoption and can help utilities cost-effectively integrate higher levels of DPV penetration (Fares and Webber 2017). Together, DPV and building energy technologies could help grids achieve deep decarbonization ${ }^{2}$ more quickly and cost-effectively (Jenkins, Luke et al. 2018, Cole, Greer et al. 2021).

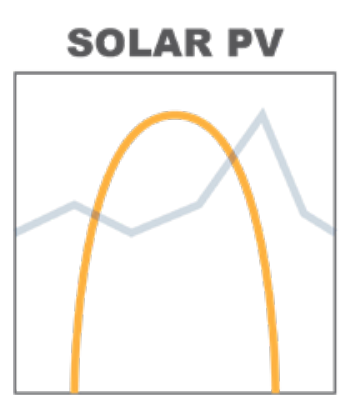

$\mathrm{PV}$ is the most cost-effective and scalable technology for on-site emissions-free generation.

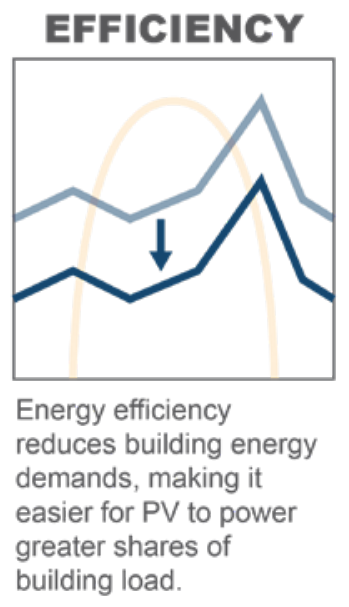

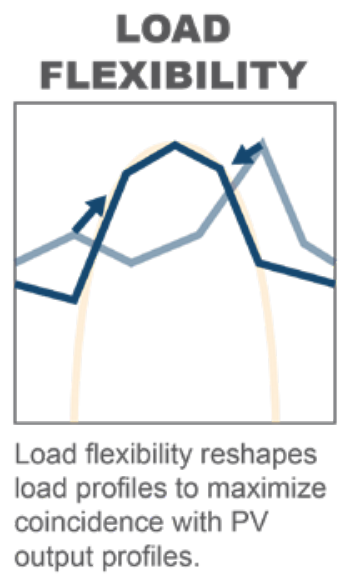

output profiles.

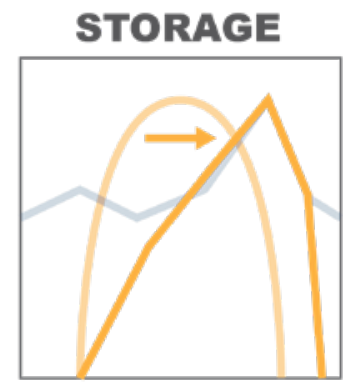

Storage stores and shifts PV output, ensuring that PV can power loads outside of the diurnal solar cycle.

Figure 1. Synergistic functions of DPV and building energy technologies

\footnotetext{
${ }^{1}$ For the purposes of this report, the term building energy system broadly refers to all infrastructure determining a building's energy use, including grid interconnections, on-site generators, energy conversion devices, energized devices, and building thermal mass. The term building energy technologies refers to devices adopted to optimize building energy use, including energy-efficient devices, flexible loads, and battery storage.

${ }^{2}$ Grid decarbonization costs are projected to increase rapidly after around 80 or $90 \%$ decarbonization (Denholm et al. 2021). Deep decarbonization refers to decarbonization above that threshold, with the end goal of achieving $100 \%$ grid decarbonization.
} 
In this report, we explore the role of building energy technologies and DPV in transforming and decarbonizing the U.S. electric grid. We purposefully take a grid perspective rather than an end user perspective. The grid perspective requires evaluating building energy technologies and DPV in two dimensions (Figure 2). The first dimension is how these technologies are deployed. The deployment of building energy technologies and DPV depends on the idiosyncratic and autonomous decisions of millions of individuals about whether to adopt these technologies. We use the term demand-side resources to refer to building energy technologies and DPV that are adopted and could potentially provide grid services. The second dimension is how these resources are operated. For the purposes of this report, we use the term. As we discuss throughout this report, demand-side services can be elicited through passive measures, such as electricity rate structures, or actively solicited by directly incentivizing specific technology operations.

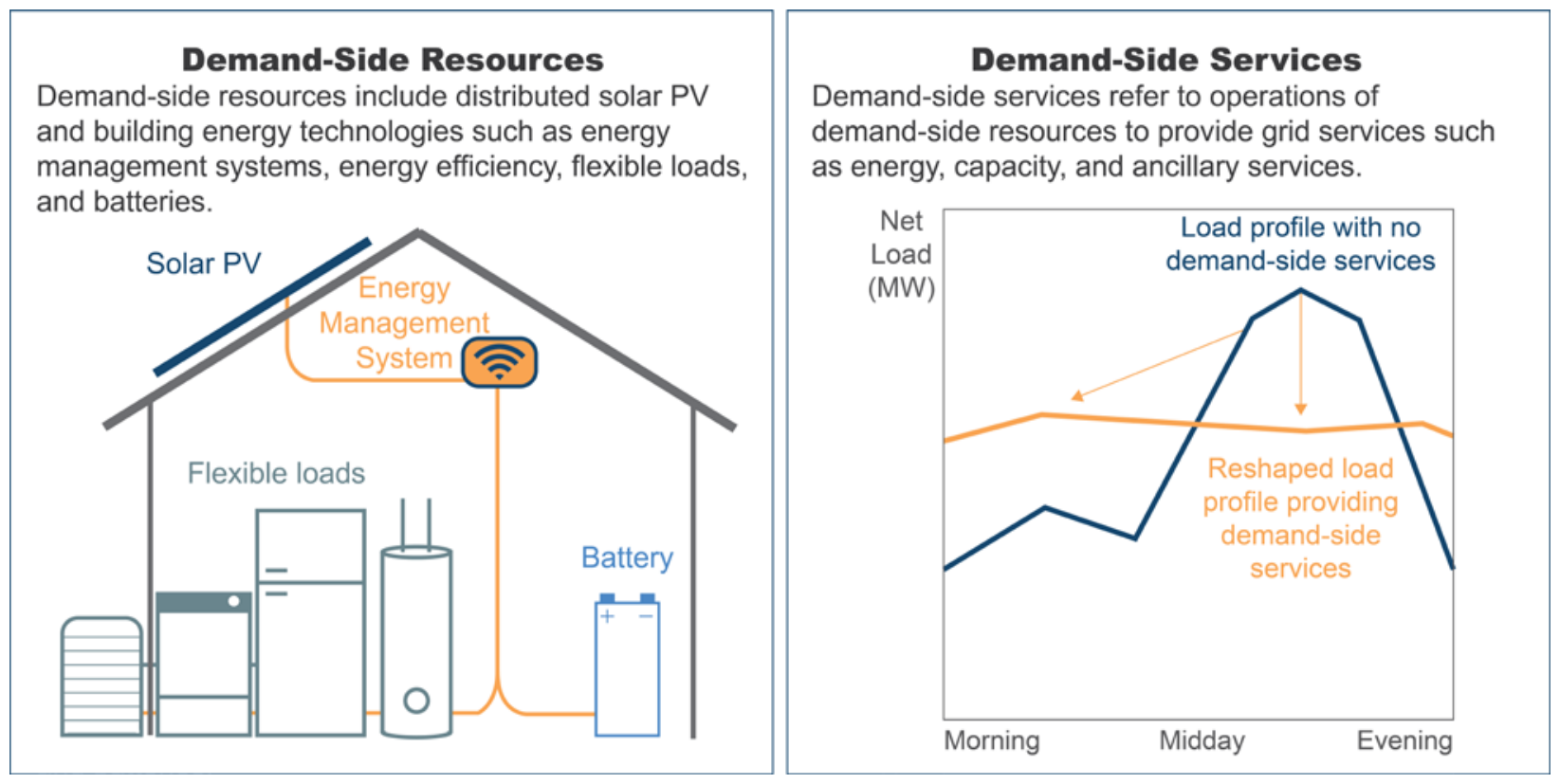

Figure 2. Demand-side resources and services

Both dimensions are critical from the grid perspective. Demand-side resources that provide demand-side services are critical components of deep decarbonization pathways (Jenkins, Luke et al. 2018, Larson, Greig et al. 2020, Cole, Greer et al. 2021). Conversely, demand-side resources that do not provide demand-side services can cause issues in grid operations and planning and can be counterproductive to deep decarbonization efforts (Morstyn, Farrell et al. 2018). The key question, then, is how to drive both the beneficial adoption of demand-side resources and the beneficial use of those resources to provide demand-side services. This report is an exploration of the potential benefits of and barriers to resolving that question.

Demand-side resources and services must be analyzed in terms of tradeoffs between demandside and centralized grid solutions (Eckman, Schwartz et al. 2020). Demand-side resources entail disadvantages in economies of scale relative to centralized grid assets (Burger, Jenkins et al. 2019). Further, demand-side resources are not always good substitutes for centralized grid assets (Say, Schill et al. 2020). Hundreds or thousands of building energy technologies must be 
aggregated to provide grid services comparable to those of a single large generator (Subarrao, Fuller et al. 2013, AEIC 2018, Gundlach and Webb 2018, Fallahi and Henze 2019). Notwithstanding these disadvantages, demand-side resources will play a role in grid transformation for at least five reasons:

- Demand-side resources provide several unique benefits, such as distribution network investment deferrals, enhanced supply diversity, and local grid resiliency (Larsen and Herndon 2017, Burger, Jenkins et al. 2019).

- Demand-side resources can be installed in and on existing building spaces, thus avoiding the land-use constraints associated with centralized assets (see Section 3.3, Text Box 5).

- Building energy technology adoption does not depend strictly on energy or grid benefits. Non-energy benefits such as enhanced user comfort, experience, and security often drive technology adoption (see Section 3.2.3).

- Demand-side solutions can help achieve energy justice objectives. Demand-side resources can help low- and moderate-income customers and communities to build wealth, redress environmental justice grievances, and more actively participate in deep decarbonization (Baker 2021).

- Achieving deep decarbonization will require a diverse mix of demand-side and centralized grid assets (Jenkins, Luke et al. 2018, Teplin, Dyson et al. 2019, Clack, Choukulkar et al. 2020, Larson, Greig et al. 2020, Cole, Greer et al. 2021).

We begin with a background discussion on key trends in DPV and building energy systems. We then explore the demand-side opportunity of leveraging underutilized DPV and building energy technologies as demand-side resources providing demand-side services. We then explore barriers to this opportunity and potential game changers that could fundamentally alter the role of demand-side resources in grid transformation and deep decarbonization. We conclude by identifying key policy levers for maximizing the demand-side opportunity. 


\section{Text Box 1. Report scope limitations}

A comprehensive evaluation of building energy systems and technologies would require several studies. We limit our scope in two ways. First, we only briefly explore themes related to building infrastructure, such as building insulation, thermal mass, building materials, and new construction. In doing so, we elide the potentially significant role of advanced building construction methods and materials in shaping future building energy use. For a review of this topic, see Fallahi and Henze (2019). Second, we restrict our discussion of specific building-related topics that are covered in depth in other Solar Futures Study reports. We largely exclude industrial operations that occur in buildings, electric vehicle charging that could occur in buildings (see Ardani et al. 2021), building and grid resiliency, and specific issues related to technology deployment in low-income housing (see Heeter et al. 2021).

Ardani, Kristen, Chad Hunter, Caley Johnson, and Sam Koebrich. 2021. Maximizing Solar and Transportation Synergies. Golden, CO: National Renewable Energy Laboratory. NREL/TP6A20-80779. TP-6A20-80779. https://www.nrel.gov/docs/fy21osti/80779.pdf.

Heeter, Jenny, et al. 2021. Affordable and Accessible Solar for All: Barriers, Solutions, and On-Site Adoption Potential. Golden, CO: National Renewable Energy Laboratory. NREL/TP-6A20-80532. https://www.nrel.gov/docs/fy21osti/80532.pdf. 


\section{Key Trends in DPV and Building Energy Systems}

In this section, we summarize trends and prospects for near-term advances in DPV and building energy systems. We organize our discussion into five topic areas, based on high-level trends in DPV and building energy technologies: trends in building electricity use; the proliferation of DPV and building energy technologies; ICT advancements; emerging business models; and regulatory reform.

\subsection{Building Electricity Use Is Increasing}

The best available data suggest that building electricity use roughly doubled from 1980 to 2018 (EIA 2020). Building electricity use continues to rise despite ongoing improvements in energy efficiency. This rise can primarily be attributed to the growth of the U.S. building stock (Figure 3). Survey data compiled by the U.S. Energy Information Administration (EIA) suggests that building square footage in the United States increased by about 70\% from 1980 to 2018, mostly from new home construction. Secondary factors driving increased building energy use include the proliferation of small-scale, high-tech devices (e.g., laptops, smartphones) and demographic shifts to warmer climates with larger air-conditioning loads (EIA 2020).
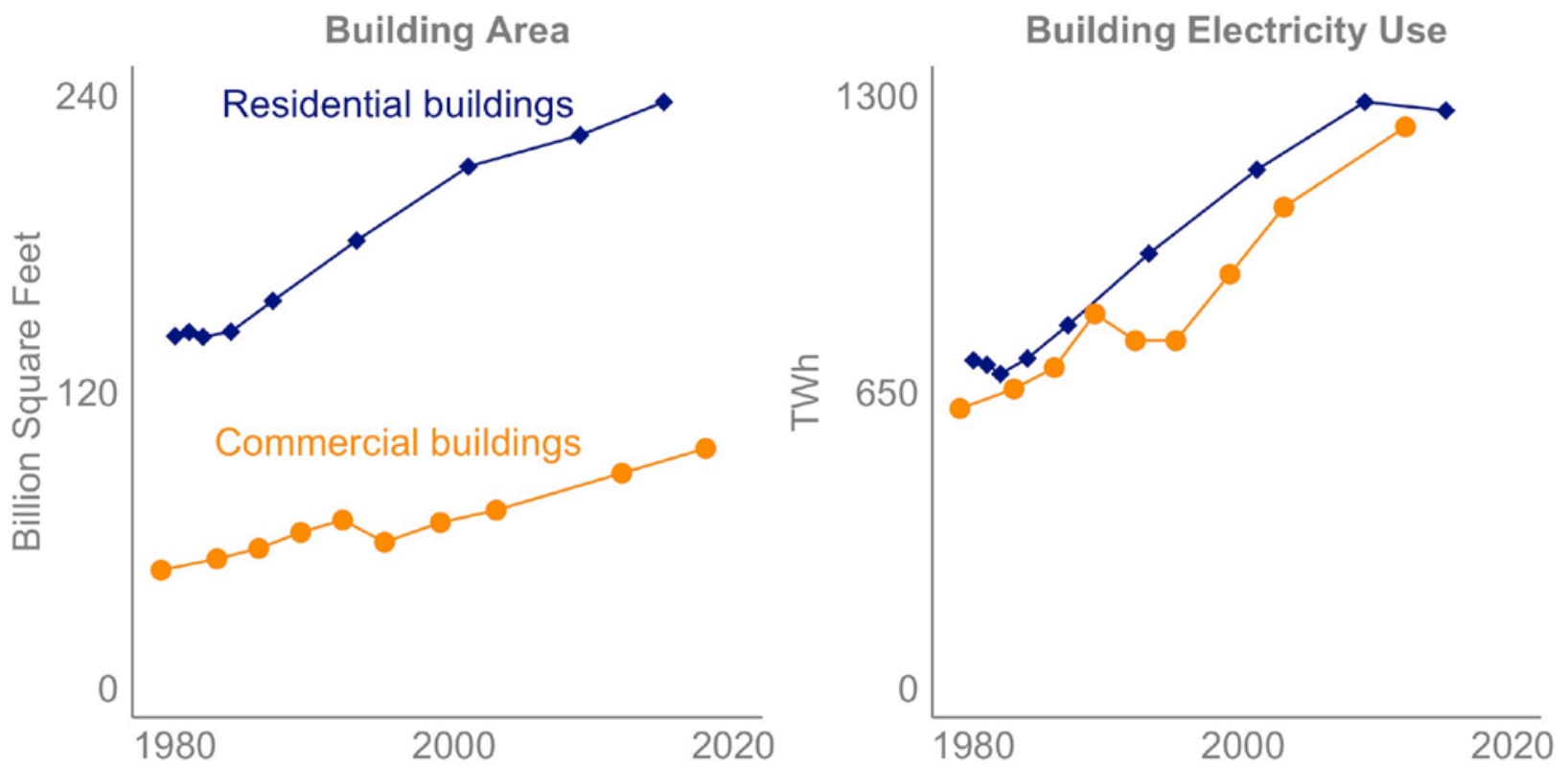

Figure 3. U.S. building square footage (left) and electricity use (right) from 1979 to 2018, based on data from the U.S. EIA's residential and commercial building energy surveys ${ }^{3}$

Building electricity use is projected to increase for the foreseeable future, albeit at a slower pace. The U.S. EIA projects building electricity use to increase by about $22 \%$ from 2020 to 2050 (EIA 2021). One driver of this projected increase is an ongoing demographic shift toward warmer climates. Another factor is the electrification of loads previously powered by on-site combustion

\footnotetext{
${ }^{3}$ Some year-over-year differences may be attributable to changes in methodologies. Estimated square footage values are omitted for 1997 and 2005. Estimates in these years deviate significantly from the evident trend from 1980 to 2010.
} 
of fossil fuels - particularly space and water heating - which represent about half of current building energy use (EIA 2020). Electrification is being actively pursued to reduce buildingenergy-driven emissions (Dennis, Colburn et al. 2016, Mahone, Li et al. 2019, Urban Green 2020). The share of residential and commercial building loads powered by electricity could increase from around $46 \%$ in 2021 to more than $60 \%$ in 2050 (Mai, Jadun et al. 2018), perhaps even approaching $100 \%$ by 2050 (Steinberg, Bielen et al. 2017). We discuss electrification in further depth in Section 5.1.1.

\subsection{DPV and Building Energy Technologies Are Proliferating}

DPV deployment depends on the adoption decisions of millions of individual actors. These decisions are based on numerous idiosyncratic factors, including financial motivations, environmental preferences, and the desire to use new technology (Wolske, Stern et al. 2017). Rapidly declining DPV prices are accelerating DPV adoption by reducing payback periods. From 2010 to 2019, median DPV system prices declined by about 50\%-60\% (Barbose, Darghouth et al. 2020), while installed capacity increased by more than a factor of 20 . With about 2.4 million systems installed by 2019 (Barbose, Darghouth et al. 2020), the U.S. DPV market has used about $3 \%$ of the technical potential rooftop DPV capacity.

Building energy technologies are similarly proliferating, largely due to declining costs and shorter payback periods. Energy-efficient device premiums have declined, even as devices have become more efficient (King and Perry 2017). Nadel et al. (2015) estimate that energy efficiency improvements reduced U.S. energy use by around 30\% from 1980 to 2015 . Additional potential improvements in energy efficiency on the order of $10 \%-40 \%$ are likely, and improvements on the order of $50 \%-60 \%$ are possible. Building automation technologies that enable load flexibility have also declined in price (King and Perry 2017). The share of commercial building space controlled by building automation systems rose from about $22 \%$ in 2003 to $43 \%$ in 2020 (Sofos, Langevin et al. 2020). The rise of small, communication-capable or "smart" devices could enable automation, coordination, and aggregation in residential buildings. By 2020 in the United States, around 50 million homes had smart home devices (Hledik, Faruqui et al. 2019). Important examples include smart thermostats, smart space and water heaters, and home "assistants" (e.g., Amazon Alexa, Google Home) that can serve as small-scale energy management hubs. Finally, from 2015 to 2020, median per-unit battery prices declined by about $7 \%$ and $25 \%$ for residential and commercial-scale batteries, respectively (Holden, Curtin et al. 2020). Distributed energy storage capacity increased from less than $100 \mathrm{MW}$ in 2016 to about $980 \mathrm{MW}$ in 2020 (Kellison, Kolo et al. 2020).

\subsection{ICT Advancements Have Facilitated Technology Automation, Coordination, and Aggregation}

Building energy systems use various controls to optimize building energy technology performance. For the purposes of this report, we group the functions of these controls into three levels, defined in Figure 4: automation, coordination, and aggregation. Technology automation eliminates the need for human intervention and can result in better utilization of building energy systems. Technology coordination can maximize the benefits of demand-side resources by mitigating issues of interference among competing technologies and maximizing synergies among complementary technologies. Finally, aggregation can leverage demand-side resources at the scales required to provide grid services. A fourth potential category, building energy system 
orchestration, coordinates energy systems across multiple buildings. We explore the possibilities of orchestration in Section 5.1.2.
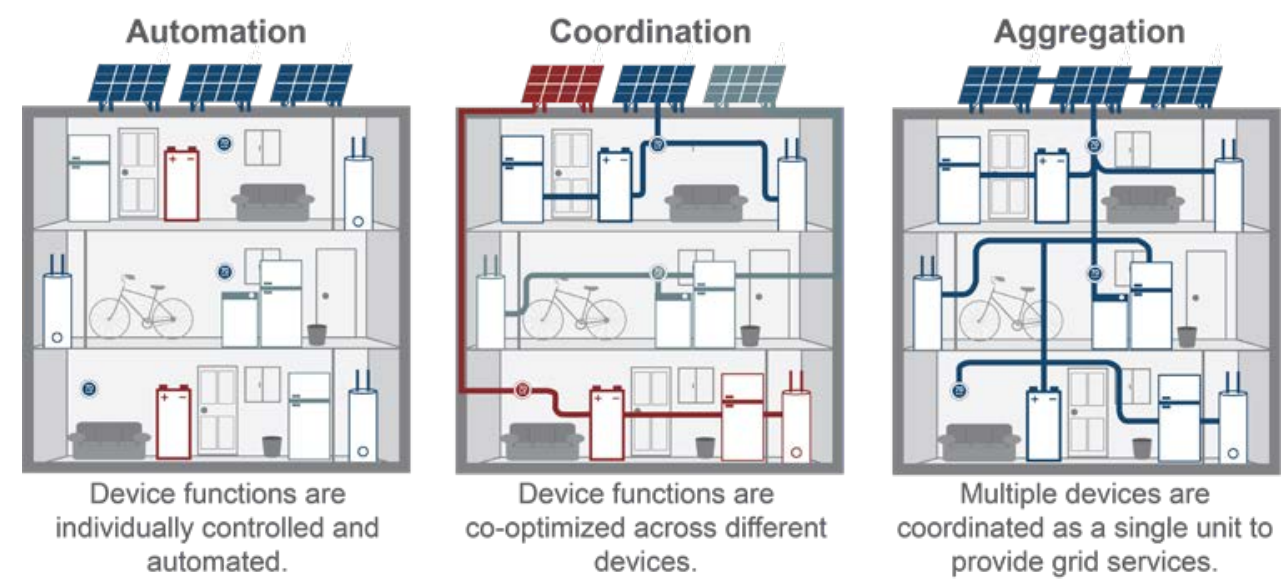

Figure 4. Building energy technology automation, coordination, and aggregation

Building automation and coordination systems have been available for decades (Sayed and Gabbar 2018, Sofos, Langevin et al. 2020). However, these systems only control about half of floor space in large commercial buildings ( $>50,000$ square feet) and $8 \%$ of floor space in small commercial buildings $(<50,000$ square feet), and are rare in residential buildings (Sofos, Langevin et al. 2020). Further, deployed building automation and coordination systems are either relatively rudimentary or underutilized (Sofos, Langevin et al. 2020). Existing systems primarily follow prespecified rules and do not respond to changing building thermal or occupancy conditions. Building aggregation has relied on similarly rudimentary approaches, such as switches that allow utilities to temporarily turn off residential thermostats and manual customerinitiated reductions in commercial and industrial loads (Surampudy, Chew et al. 2019). Partly because of these technological limitations, demand-side aggregation has historically been limited to providing peak reduction services during rare grid events (see Section 2.5).

Recent ICT advances in wireless and network communications, digital equipment operation, and cloud-based systems have significantly improved building automation, coordination, and aggregation capabilities (Hittinger and Jaramillo 2019, Sofos, Langevin et al. 2020). Modern building automation systems can dynamically automate devices using advanced sensors that detect changes in building thermal or occupancy conditions (King and Perry 2017). These systems can more effectively coordinate disparate devices in real time to prevent interference and co-optimize multiple loads (Sofos, Langevin et al. 2020). Emerging home assistants (e.g., Amazon Alexa, Google Home) can provide small-scale energy automation and coordination solutions for residential and small commercial buildings. Grid-interactive efficient buildings leverage advanced ICT coupled with energy efficiency upgrades to maximize the grid capabilities of building energy systems (Text Box 2). 


\section{Text Box 2. Grid-interactive efficient buildings}

The epitome of building energy coordination, automation, and aggregation is grid-interactive efficient building design, wherein building ICT and building energy technologies are used as interactive grid resources. Grid-interactive efficient buildings use "smart technologies and on-site [demand-side resources] to provide demand flexibility while co-optimizing for energy cost, grid services, and occupant needs and preferences, in a continuous way" (Neukomm, Nubbe et al. 2019, Satchwell, Piette et al. 2021). With proper incentives, grid-interactive efficient buildings can maximize the value of building energy systems as distributed grid assets. For comprehensive discussions of grid-interactive efficient building design, see Jungclaus et al. (2019), Neukomm et al. (2019), and Roth (2019). For a description of strategies to maximize the long-term potential of grid-interactive efficient building design, see Satchwell et al. (2021).

ICT advances enhance demand-side aggregation capabilities in at least two ways. First, ICT advances can enhance the coordination and aggregation of loads in the large commercial buildings that already provide grid services (Hledik, Faruqui et al. 2019, Jungclaus, Carmichael et al. 2019). For instance, more effective communication networks could allow utilities to dynamically control large commercial loads to continuously provide grid services, rather than only calling on such services in rare grid events. Second, ICT advances could increase the value of residential and small commercial aggregation (Hledik, Faruqui et al. 2019). For instance, emerging distributed energy resource management systems have significantly improved utility control over large numbers of small-scale demand-side resources (Cook, Ardani et al. 2018).

Through ICT, building energy systems can more effectively exploit the synergies between building energy technologies and DPV. Flexible loads can be automated and coordinated to maximize the on-site use of DPV and minimize DPV exports to the grid. Energy storage operations can be automated and coordinated to store and shift DPV output, maximizing the value of DPV to buildings or to the grid. A large body of literature, reviewed in O'Shaughnessy et al. (2018), shows how building energy technology automation and coordination can increase the value of DPV, suggesting that automation and coordination could drive higher levels of future DPV deployment.

Further, ICT can directly increase the grid capabilities of DPV systems. Through smart inverters, DPV systems can be remotely automated, coordinated, and aggregated to provide grid services (AEIC 2018). DPV can be temporarily curtailed in response to grid needs (e.g., voltage violations) (Horowitz, Peterson et al. 2019). Alternatively, DPV can be purposefully curtailed on an ongoing basis to create "headroom," within which DPV output can be modulated to provide ancillary services.

The ICT-driven increase in building automation, coordination, and aggregation capabilities has not translated to a proportional increase in the use of these controls. Many buildingsparticularly in the residential sector - underutilize their building automation systems, typically by configuring these systems through rule-based controls to meet short-term thermal and ventilation needs (Sofos, Langevin et al. 2020). As a result, the long-term energy impacts of the rise of ICT in building and grid systems are not yet understood. ICT advances should, all else equal, reduce building energy demands through automation, coordination, and aggregation. However, if underutilized, a proliferation of ICT-enabled devices could increase building loads, given that smart devices demand more energy than conventional devices (Hittinger and Jaramillo 
2019). Further, the rise of ICT-enabled devices may result in hidden building loads by increasing cloud-based computing and data processing requirements in data centers (Hittinger and Jaramillo 2019).

\subsection{Emerging Business Models Have Yielded More Reliable and Valuable Demand-Side Services}

The ICT advances discussed in Section 2.3 are converting DPV and building energy technologies into demand-side resources capable of providing grid services. However, ensuring that these resources provide grid services requires business models that incentivize end users to operate these technologies in ways that benefit the grid (Morstyn, Farrell et al. 2018). All demand-side service models face the same basic challenge: incentivizing owners of demand-side resources to give up some autonomy over those resources (Morstyn, Farrell et al. 2018, Roberts, Adams et al. 2020). Financial incentives embedded in rate structures are one of the simplest approaches for incentivizing demand-side services. Essentially any rate that charges different prices for electricity at different times can incentivize demand-side services (O'Shaughnessy, Cutler et al. 2018). We will discuss the key role of electricity rate structures throughout this report.

ICT advances are driving the proliferation of new demand-side service business models. These business models include:

- Demand response: Until recently, demand response has been the only large-scale business model for demand-side services. In demand response, a utility or third-party vendor contracts with retail electricity customers who agree to temporarily curtail loads. ${ }^{4}$ Demand response is a well-established approach for using demand-side services, with around $50 \mathrm{GW}$ of enrolled capacity (Kellison, Kolo et al. 2020). However, conventional demand response programs only use that capacity during rare grid events, particularly for peak reduction during annual grid peaks.

- Automated demand response: Utilities and third-party vendors are increasingly embracing ICT as a way to automate demand response services (Surampudy, Chew et al. 2019). Automated demand response could increase the frequency of demand-side service provision from a few rare grid events to an ongoing daily or hourly provision of a broader scope of services.

- Microgrids: A microgrid is a cluster of building energy systems that are interconnected to the grid but capable of operating independently from the grid (Hirsch, Parag et al. 2018). Utilities and vendors can automate and control smart building energy technologies within microgrids for the provision of grid services. Microgrids can provide additional benefits in the form of resiliency. In the event of broader grid outages, such as during natural disasters, microgrids are capable of islanding from the main grid and continuing to power critical loads.

- Virtual power plants: A virtual power plant refers to clusters of demand-side resources that may be spatially dispersed (unlike a microgrid, which is a collection of collocated devices). Utilities and vendors can use centralized management systems to automate and coordinate the function of aggregated demand-side resources in a virtual power plant.

\footnotetext{
${ }^{4}$ Some demand response programs also engage small-scale generators, such as backup diesel generators, though such assets represent less than 10\% of demand response capacity (Surampudy et al. 2019).
} 
Several utilities have implemented virtual power plant pilots, and third-party vendors have begun to offer virtual power plant services (Spector 2020).

- Community energy: In the community energy model, a community organization manages a microgrid or a fleet of demand-side resources on a community's behalf (Parra, Swierczynski et al. 2017). Community energy systems have been an integral part of clean energy transitions in several European countries (Hockenos 2020), but this approach has not been common in the United States. ${ }^{5}$

- Peer-to-peer networks: A final approach is peer-to-peer networks, which could allow demand-side resource owners to create bottom-up markets for demand-side resources (Morstyn, Farrell et al. 2018). In peer-to-peer networks, owners of demand-side resources sell demand-side services directly to other end users via market platforms such as Blockchain. Peer-to-peer energy networks are a nascent approach, with only a few pilots actively being tested in the United States.

\subsection{Regulatory Reforms Have Mitigated Some Barriers to Demand- Side Services}

Demand-side resources face numerous barriers to the provision of grid services to utilities and the sale of such services in wholesale energy markets (see Sections 4.2-4.3). Although most of these barriers remain, several recent regulatory reforms suggest that these barriers may erode in the near future, including:

- Rate reforms: Several state public utility commissions have approved rate structures with more dynamic (i.e., time-variant) rates (Burns, Bialecki et al. 2020). All else equal, dynamic rates increase incentives for the provision of demand-side services. However, these early rate reforms have faced numerous practical challenges (see Section 4.2).

- Smart inverter requirements: Several states and utilities have implemented rules requiring DPV to be equipped with smart inverters that can be controlled by grid operators (AEIC 2018). Early pilot programs suggest that smart DPV systems can provide various distribution grid services, and that the value of these services will increase as more DPV systems are integrated onto the grid (AEIC 2018).

- All-source procurement: Several states now require regulated utilities to solicit grid services through technology-neutral or "all-source" procurement mechanisms (Wilson, O'Boyle et al. 2020). All-source procurement can eliminate biases of conventional utility solicitations toward conventional centralized assets (Teplin, Dyson et al. 2019). Allsource procurements have already increased the use of demand-side resources in utility portfolios in California.

- Federal orders: The Federal Energy Regulatory Commission has issued several recent orders facilitating demand-side resource access to wholesale electricity markets (Burns, Bialecki et al. 2020). The most recent order, Order 2222, requires regional transmission operators to ensure that market rules facilitate the provision of services by aggregated demand-side resources.

\footnotetext{
5 The community energy model is distinct from the community solar model commonly deployed in the United States. In community solar, the output of a shared solar asset is credited to a group of subscribing customers, but the community solar asset does not necessarily provide demand-side services.
} 


\section{The Demand-Side Opportunity}

Despite the trends discussed in Section 2, demand-side resources remain underutilized. Only about $25 \%$ of potential demand-side resource capacity is enrolled in demand response programs (Kellison, Kolo et al. 2020), and even those resources are only used in a limited number of grid events per year. Similarly, as already noted, less than half of building space uses building automation and coordination systems, and these systems are generally underutilized relative to their full technological potential (Sofos, Langevin et al. 2020). Further, there are about 7,700 square kilometers of DPV-viable rooftop space in the United States (Gagnon, Margolis et al. 2016), an area larger than the state of Delaware. Roughly $97 \%$ of that space remains available. ${ }^{6}$ The vast majority of demand-side resource potential is unutilized or underutilized.

Unutilized and underutilized demand-side resources present opportunities to decarbonize grids more quickly and cost-effectively. In this section, we first explore the magnitude of this opportunity in terms of potential future deployment of demand-side resources. We then discuss the benefits of the demand-side opportunity in terms of grid cost savings, renewable energy integration, decarbonization, and grid resiliency.

\subsection{The Role of Demand-Side Resources}

On their own, demand-side resources and services are insufficient for deep decarbonization. The full technical potential of DPV equates to about $39 \%$ of U.S. electricity demand (Gagnon, Margolis et al. 2016), and even ambitious improvements in energy efficiency can only reduce emissions by around $50 \%-60 \%$ (Nadel and Ungar 2019). In addition, the full existing technical potential of all flexible loads only equates to about $20 \%$ of grid peak demand (Hledik, Faruqui et al. 2019). Although grids have become increasingly decentralized, there is no viable deep decarbonization pathway that does not rely primarily on large-scale, centralized solutions (Jenkins, Luke et al. 2018). Hence, the primary role of demand-side resources is to complement centralized supply-side solutions.

Demand-side resources can complement supply-side solutions in three primary ways, as summarized in Figure 5: reducing grid net load or "lowering the bar," enhancing grid flexibility, and creating pathways for electricity customer engagement.

\begin{tabular}{|c|c|c|}
\hline Lowering the Bar & Enhancing Grid Flexibility & Customer Engagement \\
\hline $\begin{array}{l}\text { Demand-side resources can } \\
\text { "lower the bar" for deep } \\
\text { decarbonization by reducing } \\
\text { grid net load (load after } \\
\text { factoring out DPV) }\end{array}$ & $\begin{array}{l}\text { Demand-side resources can } \\
\text { reshape and modulate load } \\
\text { profiles to provide demand-side } \\
\text { grid flexibility }\end{array}$ & $\begin{array}{l}\text { Demand-side resources provide } \\
\text { a pathway for customers to } \\
\text { engage directly in deep } \\
\text { decarbonization }\end{array}$ \\
\hline
\end{tabular}

Figure 5. Primary functions of demand-side resources

\footnotetext{
${ }^{6}$ The best available data suggest that about $30 \mathrm{GW}$ of rooftop PV have been deployed out of a technical potential of about $1,100 \mathrm{GW}$, meaning that about $2.7 \%$ of rooftop technical potential has been exploited. This provides only a rough approximation of the rooftop space that has been exploited.
} 


\subsubsection{Lowering the Bar}

Demand-side resources can "lower the bar" by reducing the net load that must be served by grids. In particular, DPV and energy efficiency lower the bar by reducing the aggregate volume of the net load. Storage and load flexibility can lower the bar by reducing peak demand, thereby reducing the need for flexible capacity to meet that peak demand. Further, load flexibility and energy storage can be configured to maximize on-site use of DPV (i.e., minimize DPV exports to the grid), thus enhancing the capabilities of DPV to reduce net load (O'Shaughnessy, Cutler et al. 2018). By maximizing on-site DPV use, building energy technologies can increase the value proposition of DPV, mitigate the adverse impacts of DPV power flows on distribution networks, and enable higher DPV penetration levels (Fares and Webber 2017).

The New Buildings Institute modeled the potential impacts of lowering the bar through high levels of DPV penetration, and they found that building contributions to grid emissions fall as greater shares of building load are met through on-site renewable energy generation (Figure 6). Their modeling suggests that most buildings reduce grid emissions when at least $70 \%$ of demand is met through on-site renewable energy. They found that buildings that meet more than $70 \%$ of demand through on-site renewable energy can be carbon negative. That is, buildings with high DPV use can reduce, rather than contribute to, grid emissions. The modeling results suggest that DPV could drive decarbonization by reducing the net load served by centralized grid assets.

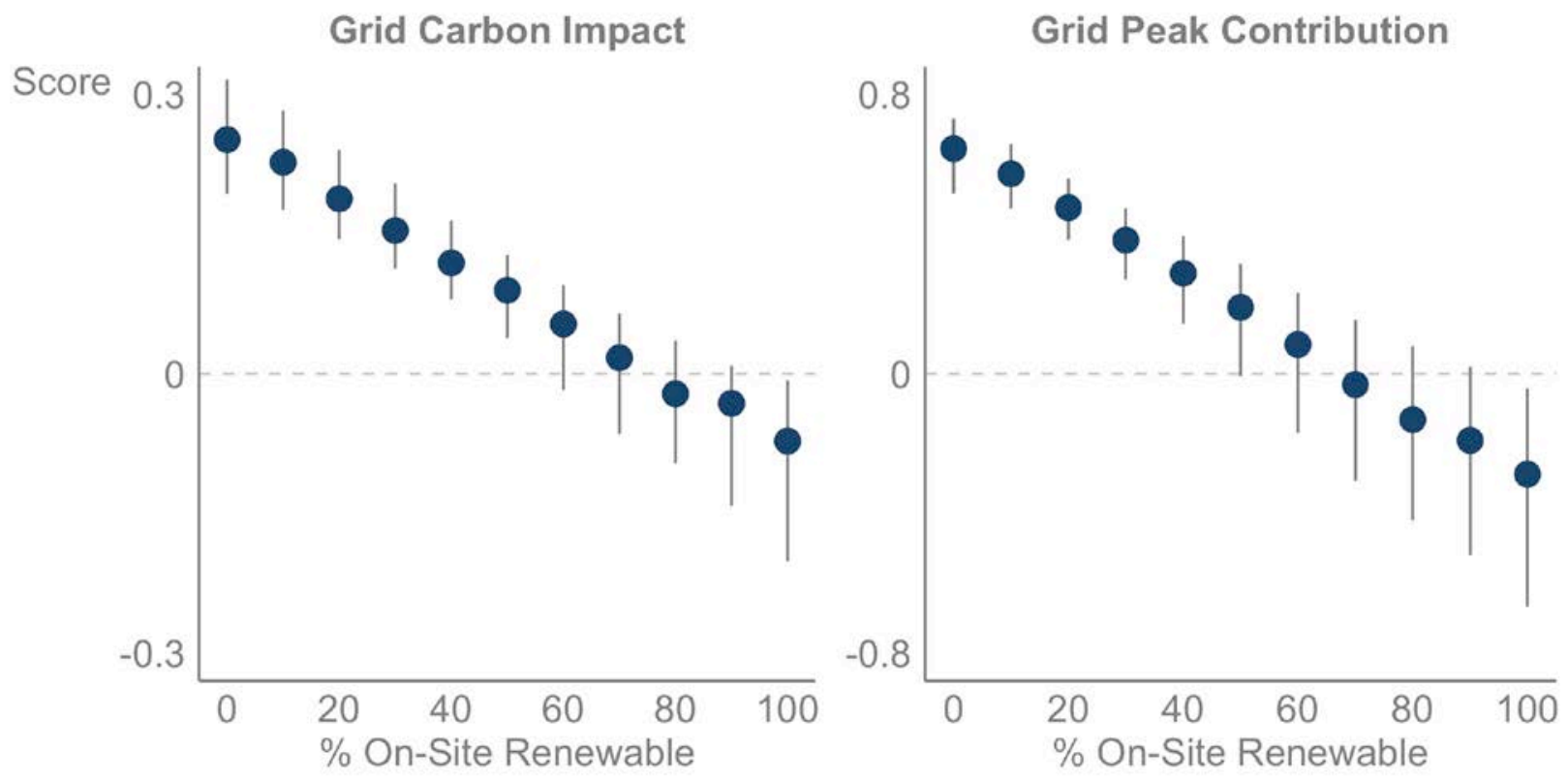

Figure 6. The effect of on-site renewables on grid carbon impact (left) and building contributions to peak demand (right)

The grid carbon impact and grid peak contribution scores are unitless metrics developed by the New Buildings Institute (NBI 2020). Figure based on data provided by the Institute. 


\subsubsection{Enhancing Grid Flexibility}

To unpack the concept of enhanced grid flexibility, it is important to understand that supply and demand must be constantly and instantaneously balanced to ensure reliable grid operations. Any deviation on one side of the supply/demand equation must be met by a proportional change on the other side of the equation. The ability of a grid to respond to changes in supply and demand is known as flexibility. Historically, flexibility has been - almost exclusively - a supply-side responsibility. Grids and markets have been designed such that fluctuations in demand are always balanced by purposeful changes in supply, and only rarely the reverse. However, with the rise of variable renewable energy generators (e.g., solar, wind), firm supply-side assets have increasingly been required to compensate not only for fluctuations in demand, but also for fluctuations in supply. The increasing need for supply-side flexibility has increased grid operational costs and represents a key challenge for renewable energy integration (Denholm, Arent et al. 2021).

Demand flexibility can reduce grid operational and renewable energy integration costs by supplementing supply-side flexibility. Flexible loads can be curtailed, shifted, and modulated (Text Box 3) to allow electricity demand to purposefully respond to fluctuations in electricity supply. For instance, on warm, sunny days, flexible air-conditioning loads can be shifted to earlier in the day, when the grid is powered by abundant PV output, to "precool" buildings. Precooled buildings can then switch off their thermostats as the sun sets, reducing the need to ramp up centralized generators as PV plants come offline. Energy efficiency can also extend the flexibility capabilities of building energy technologies. For instance, a well-insulated, energyefficient building can increase the impacts of precooling operations by maximizing how long the building can sustain a tolerable temperature without engaging the air-conditioning unit.

\section{Text Box 3. Flexible load functions}

Flexible loads can perform three functions that could be leveraged for grid services:

- Peak reduction: Flexible loads can be temporarily curtailed or shifted away from grid demand peaks. Peak reduction can yield significant cost savings by reducing the need for grid peaking infrastructure (see Section 3.2).

- Load shaping: Building automation and coordination systems can reshape flexible load profiles in ways that provide grid value. For instance, load profiles can be shaped to better align with the availability of low-cost solar output during the day.

- Modulation: Certain flexible loads can be fluctuated on very short timescales to provide ancillary services such as frequency regulation and voltage control.

\subsubsection{Customer Engagement}

Demand-side resources provide a pathway for customers to engage directly in deep decarbonization. Individual customers can reduce their personal contributions to grid emissions by adopting DPV, energy-efficient devices, building automation systems, or other building energy technologies. Customer advocacy and community groups can mobilize customers to adopt building energy technologies that yield local community benefits while also decarbonizing the grid. For instance, Solarize campaigns are community-led initiatives to help households adopt low-cost DPV through bulk purchasing. Solarize and other similar campaigns can provide critical information resources to drive beneficial adoption. 
Customer engagement may be a particularly beneficial trait of demand-side resources in lowand moderate-income communities. Low- and moderate-income households dedicate disproportionately large shares of their income to energy expenses, a problem known as energy burden. Customer engagement can drive demand-side resource deployment in low- and moderate-income communities, thus minimizing their energy burden. In this way, customer engagement can ensure a more equitable and just distribution of the benefits of deep decarbonization and grid transformation (Baker 2021).

\subsection{The Size of the Opportunity}

Building energy technology adoption and use depend on the idiosyncratic decisions of millions of individual households and building owners. As a result, projecting the size of the demand-side opportunity is an inherently uncertain exercise. In this section, we use NREL modeling capabilities and estimates from state-of-the-art research to provide a first-order approximation of the size of the demand-side opportunity. We also explore the potential contributions for each individual technology area. Although the extent of the opportunity varies significantly across the technology areas, the modeling and available literature generally suggest that the size of the demand-side opportunity is on the order of $20 \%$ the effort required to achieve deep decarbonization (Figure 7).

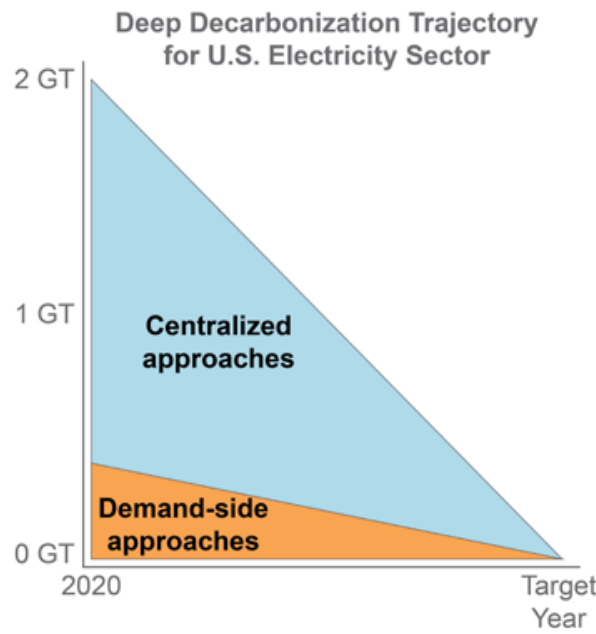

As a first-order approximation, demand-side measures could cost-effectively drive about

$20 \%$ of deep decarbonization

\section{DPV and other} distributed generators could meet around 20\% of demand with zero-carbon output.

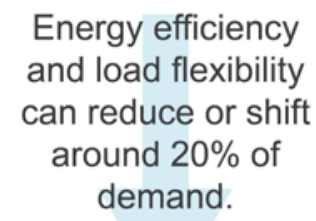

Energy efficiency and load flexibility can reduce or shift around $20 \%$ of demand.

Leveraging load flexibility can reduce deep decarbonization costs by around $20 \%$.

Figure 7. A first-order approximation of the demand-side opportunity

\subsubsection{DPV}

To explore upper-bound possibilities on the size of DPV's role, we use NREL's Distributed Generation Market Demand (dGen) Model to estimate future DPV adoption under various scenarios (see Appendix for modeling details). Our analysis suggests that future residential DPV capacity could grow from around $20 \mathrm{GW}$ in 2020 to around $100 \mathrm{GW}$ by 2030 and around 300 GW by 2050 . For comparison, the U.S. EIA projects that about $230 \mathrm{GW}$ of DPV will be installed by 2050 (EIA 2021), and Prasanna et al. (2021) (also using dGen) project 139-234 GW of DPV installed by 2050 . Under our projection, DPV would account for around $20 \%$ of all PV capacity 
projected to be deployed in the Solar Futures Study. ${ }^{7}$ In terms of energy output, our analysis suggests that DPV could meet $15 \%-25 \%$ of grid electricity demand by 2050 . Deployment projections vary by hundreds of GW depending on rate structure assumptions (Figure 8). In general, our analysis suggests significantly higher DPV deployment under an expansion of timeof-use rates with net billing, lower deployment under an expansion of demand charges, and lower deployment in the absence of any net billing.
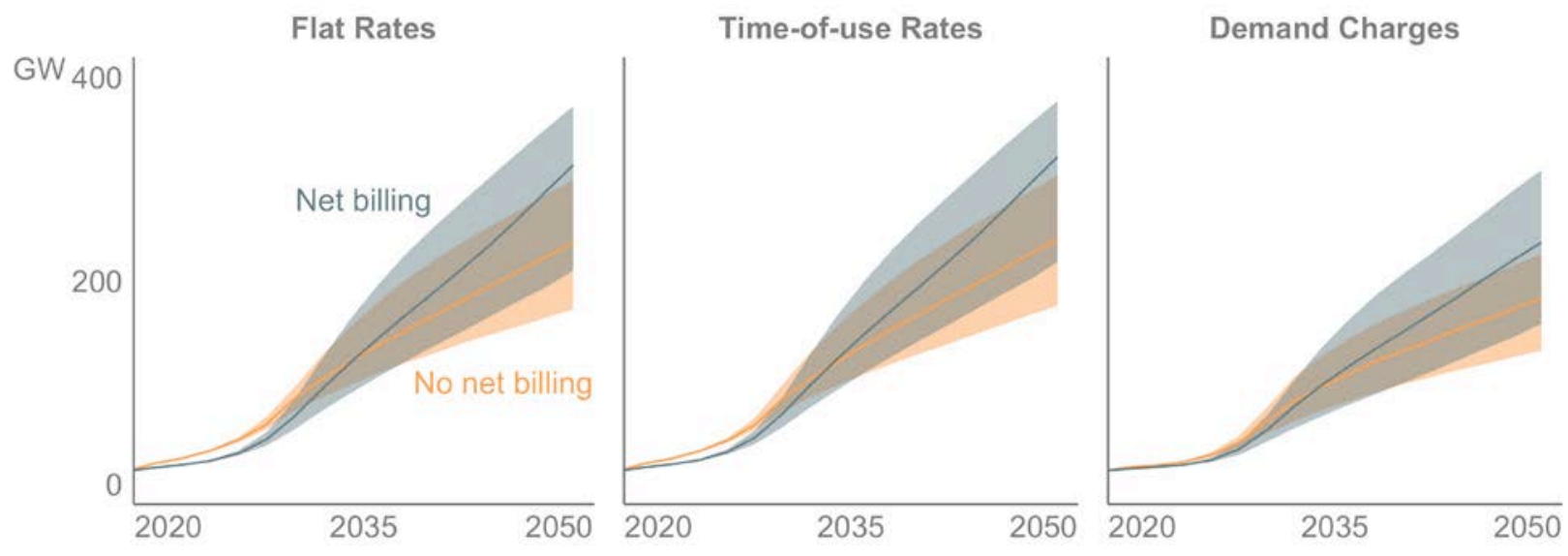

Figure 8. DPV deployment projections under three rate structure scenarios

See Appendix for modeling details.

\subsubsection{Energy Efficiency}

Constant improvements in efficiency are a defining feature of all energy systems (Smil 2017). The most reasonable assumption is that building energy efficiency will continue to improve indefinitely, both because of falling energy intensities for specific functions as well as the rise of enabling technologies such as sensors. The literature suggests that energy efficiency improvements on the order of $10 \%-40 \%$ by 2050 are likely (Fernandez, Katipamula et al. 2017, King and Perry 2017, King 2018, Langevin, Harris et al. 2019, EIA 2020, Sofos, Langevin et al. 2020), and that improvements as high as $50 \%-60 \%$ are possible (Nadel, Elliott et al. 2015, Nadel and Ungar 2019).

\subsubsection{Load Flexibility}

In theory, all thermal loads (space heating, water heating, cooling, refrigeration) can be flexibly controlled, and many nonthermal building appliances are also inherently flexible (Sun, Jadun et al. 2020). The technical potential of load flexibility is therefore a function of the percentage of flexible loads that can be controlled, the share of customers that provide load flexibility services, ${ }^{8}$ and how efficiently loads can be shifted. ${ }^{9}$

In terms of controllable load, there is currently around $200 \mathrm{GW}$ of flexible load that could provide grid services (Hledik, Faruqui et al. 2019, Kellison, Kolo et al. 2020). Tapping all

\footnotetext{
${ }^{7}$ About 1,600 GW of PV is deployed by 2050 under the Decarb+E scenario of the Solar Futures Study.

${ }^{8}$ Here, we focus on the share of customers that participate in demand-side service programs (e.g., demand response, virtual power plants). However, it is worth noting that many customers on dynamic rates (e.g., time-of-use, demand charges) "participate" in demand flexibility through behavioral changes in response to those rate structures.

${ }^{9}$ For instance, the efficiency of shifting thermal loads depends on the thermal envelope of the building. These factors are outside the scope of this study.
} 
existing flexible loads could reduce grid peak demand by as much as $20 \%$ (Fernandez, Katipamula et al. 2017, Hledik, Faruqui et al. 2019). NBI (2020) similarly estimates that load flexibility measures can reduce building peak demand by $5 \%-25 \%$. Most of this flexibility represents commercial and industrial building energy technologies. However, commercial and industrial load flexibility may be declining due to changing building occupancy patterns and the decline of U.S. manufacturing (Kellison, Kolo et al. 2020). In contrast, residential load flexibility is projected to increase from about $9 \mathrm{GW}$ in 2016 to $47 \mathrm{GW}$ in 2025, due largely to the proliferation of smart thermostats, and to a lesser extent, grid-interactive water heaters (Kellison, Kolo et al. 2020).

In terms of participation rates, around 5\%-6\% of residential and commercial customers currently provide load flexibility services (Sun, Jadun et al. 2020). Increased automation is likely to increase participation rates. Under DOE's Solar Futures Study, flexible load is projected to increase by more than a factor of 20 from 2020 to 2050, with about $16 \%$ of annual load flexibly controlled by 2050 .

Importantly, many of the technologies underlying load flexibility are being adopted for their nonenergy benefits (e.g., comfort, health, security) (Russell, Baatz et al. 2015, King 2018, Wang 2018). Smart devices adopted for non-energy reasons could lay the technological foundation for an expanded role of flexible loads in future grids. For instance, home assistants (e.g., Amazon Alexa, Google Home) can serve as energy management systems in small buildings. By 2020, there will be around 220 billion smart building appliances deployed globally (King 2018) — most adopted for non-energy benefits.

\subsubsection{Energy Storage}

Prasanna et al. (2021) project that 5-17 GW (10-34 GWh) of distributed battery storage will be deployed by $2050 .{ }^{10}$ In comparison, Kellison et al. (2020) project that distributed battery adoption will reach around $7 \mathrm{GW}$ by 2025 , putting batteries on a trajectory for significantly higher deployment levels by 2050 . The increase in projected building-sited battery capacity does not necessarily translate to a proportional increase in demand-side services (Say, Schill et al. 2020). The reason is that building-sited batteries are primarily configured to meet building-level objectives, such as self-sufficiency and backup power, which reduce their ability to provide grid services. As a result, a unit of grid-scale battery storage can provide grid services more effectively than a unit of building-sited capacity. Say et al. (2020) estimate that as much as 50 MW of demand-side batteries would be required to provide the same grid value as a MW of gridscale capacity. Grid-scale batteries could thus displace building-sited batteries in the provision of grid services, particularly given that grid-scale battery capacity is projected to outpace distributed battery capacity by more than a factor of four (Holden, Curtin et al. 2020). This displacement is unique to batteries - energy efficiency and load flexibility have no supply-side equivalents, and Say et al. (2020) show that DPV provides a near 1:1 match for centralized PV capacity. It is therefore particularly difficult to project the potential contribution of building-sited batteries to grid transformation and deep decarbonization.

\footnotetext{
${ }^{10}$ Although other energy storage technologies may emerge at scale—such as thermal and ice storage-we focus on batteries here.
} 


\subsection{The Value of Demand-Side Resources}

Demand-side resources generate grid value by reducing the need for centralized grid services in the near term and reducing the need for new investments in centralized grid assets in the long term (Eckman, Schwartz et al. 2020). The ability of demand-side resources and services to displace centralized resources and services can generate significant savings in grid operational and capital costs (Text Box 4). Demand-side resources can mitigate the costs associated with variable renewable energy integration (Kassakian and Schmalensee 2011, Subarrao, Fuller et al. 2013, Stoll, Buechler et al. 2017, Jenkins, Luke et al. 2018, Hledik, Faruqui et al. 2019, Joskow 2019, Neukomm, Nubbe et al. 2019, Clack, Choukulkar et al. 2020). Under DOE's Solar Futures Study, demand flexibility reduces the incremental cost of achieving a fully decarbonized grid by 2050 by $22 \%$ ( $\$ 49$ billion). This system cost reduction equates to an economic value of about $\$ 20 / \mathrm{MWh}$ of flexible load. Grid cost savings translate to reduced electricity costs for rate payers in general, and for building energy technology adopters in particular.

\section{Text Box 4. Grid cost savings using building energy systems as a grid resource}

Nadel et al. (2015) estimate that energy efficiency improvements alone save U.S. electricity customers about $\$ 800$ billion/year (based on efficiency gains over a 35-year period). Data from EIA-861 suggest that savings from utility energy efficiency programs are on the order of $\$ 2$ billion/year. Dyson et al. (2015) estimate that residential load flexibility could generate grid cost savings of $\$ 13$ billion/year, mostly from peak demand savings ( $\$ 9$ billion/year). Based on a case study in Texas, Goldenberg et al. (2018) find that residential and commercial load flexibility can avoid \$1.5 billion/year in grid capital costs and $\$ 400$ million/year in fuel costs. Hledik et al. (2019) estimate that load flexibility could save around $\$ 16$ billion/year in avoided generation capital costs ( $\$ 9.4$ billion/year), avoided energy costs ( $\$ 4.8$ billion/year), avoided transmission and distribution capacity costs ( $\$ 1.9$ billion/year), and avoided ancillary service costs ( $\$ 0.3$ billion/year). Satchwell et al. (2021) estimate that broad adoption of gridinteractive efficient building design could reduce power system costs by around $\$ 8$ billion- $\$ 18$ billion/year (based only on energy efficient and demand flexibility measures).

Teplin et al. (2019) estimate that clean energy portfolios comprising demand-side measures outcompete about $90 \%$ of proposed new-build natural gas projects in the United States, with estimated cost savings of about $\$ 29$ billion and emissions reductions of about $100 \mathrm{MtCO}_{2} /$ year. The authors show that demand-side measures play a fundamental role: without energy efficiency and load flexibility, clean energy portfolios only out-compete $25 \%$ of new-build natural gas. In the long term, clean energy portfolios with demand-side measures will increasingly compete with existing natural gas projects. Teplin et al. estimate that clean energy portfolios will out-compete $90 \%$ of new natural gas projects on operating costs alone by as early as 2035 .

In addition to providing value as a substitute for centralized resources, demand-side resources can be deployed at specific points on distribution networks to defer upgrades to grid infrastructure, reduce line losses, reduce grid congestion, and enhance building resiliency, among other locational benefits (Mims Frick, Price et al. 2021). Certain demand-side resources, particularly batteries, can also be sited strategically to compensate for the locational impacts of other resources, particularly DPV (Gupta, Pena-Bello et al. 2021). Grid planners and operators can leverage these locational values by providing incentives to site demand-side resources where those resources would provide the greatest value (O'Shaughnessy and Ardani 2020). An additional locational benefit of demand-side resources is the ability to site those resources on unutilized or underutilized building spaces, which is particularly valuable in the case of DPV (Text Box 5). 


\section{Text Box 5. Siting benefits of DPV}

DPV can be deployed in and on existing building and urban structures. In contrast, centralized PV requires development of large swathes of land, on the order of 14 acres ( 6 hectares) for a $100 \mathrm{MW}$ array (Ong, Campbell et al. 2013). By using building rooftops or underutilized developed spaces, DPV avoids the need for brown- or green-field development of centralized PV and the associated environmental risks, such as biodiversity loss (Dale, Efroymson et al. 2011, Hernandez, Easter et al. 2014, Hernandez, Hoffacker et al. 2015). * Although ground-mounted PV systems are compatible with other land uses, such as livestock grazing, large-scale PV development constrains potential land uses. Finding suitable sites for large-scale renewable energy projects may become a long-term challenge for deep decarbonization (Larson, Greig et al. 2020). Rooftop DPV also provides additional building shading in the summer, which can reduce the urban heat island effect, reduce ambient temperatures, and reduce heat-related illnesses in cities (Masson, Bonhomme et al. 2014).

* It should be noted that the biodiversity risks of PV development are generally considered negligible.

Finally, building energy technologies can be leveraged to improve grid resilience - the ability of a grid to maintain operations through critical events such as natural disasters. Grid operators can strategically deploy specific building energy technologies and microgrids at specific grid locations that are vulnerable to outages to enhance grid resiliency. Building energy technologies can also ensure reliable operations during crises at critical facilities (e.g., healthcare facilities, airports, community centers). Building energy technologies also increase grid supply diversity, making grids less vulnerable to outages in any one asset. 


\section{Barriers}

In this section, we explore six groups of barriers that could extend the underutilization of demand-side resources and services. We begin by discussing a broad class of barriers to the beneficial adoption of demand-side resources. However, in the long term, the primary barriers are those that prevent demand-side resources from providing demand-side services. These barriers comprise the majority of our discussion.

\subsection{Barriers to Beneficial Adoption of Demand-Side Resources}

Building energy technology deployment depends on the idiosyncratic adoption decisions of millions of individual households and building managers. In some cases, technology adoption is not beneficial to those individuals. For instance, DPV adoption may not be beneficial for a household that is mostly shaded by a large tree. However, in many cases, individuals will choose not to adopt despite the evident benefits of adoption. Barriers to beneficial adoption include:

- Upfront costs with long-term benefits: Upfront cost premiums are generally the primary barrier to building energy technology adoption. Upfront costs can be particularly problematic in the case of retrofits, given that many building technologies are long-lived (>10 years) assets (Kerr and Platt 2020). Homeowners and building managers may be reluctant to replace existing assets with remaining years of useful service, even if the opportunity costs of doing so are offset by the benefits.

- Psychological biases: Even where cost premiums are negligible, decision makers may still forego beneficial adoption due to a host of psychological biases. Sussman and Gifford (2014) identify seven such biases, including limited cognition (lack of understanding about the benefits of technology adoption) and social influence (individuals are less likely to adopt building energy technologies if they have not seen their peers do so).

- Split incentives: About a third of residential buildings, and most commercial buildings, are leased or under mixed ownership (Bird, Gagnon et al. 2016, U.S. Census 2020). Split incentives occur in mixed-ownership situations when one party pays for technology adoption, but another party benefits. With split incentives, cost-responsible parties (typically building owners) have no incentive to invest in technologies that would benefit the other party (Bird, Gagnon et al. 2016). Split incentives are particularly common in low-income housing, multifamily housing, and commercial and industrial buildings.

- Inequitable technology adoption: Low- and moderate-income households are less likely to adopt building energy technologies than high-income households (Barbose, Forrester et al. 2020, Brown, Soni et al. 2020). Inequitable adoption could force regulators to address inequities through rate reforms that could reduce incentives for building energy technology adoption (Welton and Eisen 2019). Further, inequitable adoption and perceived energy justice issues could undermine the social and political acceptability of demand-side resources.

Commercial and industrial buildings face a unique set of barriers to beneficial adoption. In addition to split incentives, many commercial and industrial buildings have complex ownership structures that add logistical hurdles to DPV adoption (Bird, Gagnon et al. 2016). Further, although many states, local permitting jurisdictions, and utilities streamline permitting and 
interconnection processes for DPV systems, the capacity thresholds often exclude mid-scale commercial and industrial systems (e.g., $>10 \mathrm{~kW}$ ). As a result, commercial and industrial DPV systems are often subject to permitting and inspection requirements designed for utility-scale systems without benefiting from the economies of scale of utility-scale projects. See Bird et al. (2016) for further discussion of unique barriers to mid-scale DPV.

\subsection{Utility Rate and Business Model Reform Challenges}

Many states and utilities have begun to explore rate reforms to implement dynamic rates (e.g., time-of-use, demand charges) in response to changing grid and technological contexts (Burns, Bialecki et al. 2020). Dynamic rates provide more accurate price signals about time-varying grid costs and could induce beneficial adoption of demand-side resources and provision of demandside services (Hledik, Faruqui et al. 2019, Seel, Mills et al. 2020).

The theoretical promise of rate reform is tempered by practical challenges. Rate designers are required to design rates that balance competing objectives, namely, efficiency, simplicity, and equity (Bonbright 1961). Historically, rate makers have erred on the side of simplicity, as evidenced by the prevalence of inefficient yet simple flat volumetric rates (Seel, Mills et al. 2020). Dynamic rates are inherently more complex and have met early resistance from customers and customer advocates (Burns, Bialecki et al. 2020, O'Shaughnessy and Ardani 2020). Dynamic rates may compromise rate equity. Specifically, dynamic rates could harm low- and moderate-income households with relatively inflexible electricity demand (Powells and Fell 2019). As a result, dynamic rates could reduce electricity costs for building energy technology adopters at the expense of low- and moderate-income households (Welton and Eisen 2019, White and Sintov 2020). Further, certain rate structures - particularly demand charges - increase the risk of bill "shock," where customers face exorbitant costs due to their lack of understanding of how electricity costs vary over time.

Several states and utilities are exploring more fundamental changes to utility business models in response to changing grid and technological contexts (Cross-Call, Gold et al. 2018). In some cases, these reforms are intended to address aspects of conventional utility business models that are antithetical to demand-side services (Text Box 6). Utility business model reform poses a new set of challenges, such as the potential failure of competitive markets to provide energy services to disadvantaged communities. See Cross-Call et al. (2018) for a more comprehensive discussion of utility business models and the challenges of business model reform. 


\section{Text Box 6. Demand-side services under conventional utility business models}

Conventional regulated utility business models are antithetical to demand-side services (Larsen and Herndon 2017, Cross-Call, Gold et al. 2018, Teplin, Dyson et al. 2019). Following are some examples of the conflict between regulated utility business models and demand-side services:

- For vertically integrated utilities, customer- or third-party-owned demand-side resources compete directly with utility-owned generation assets.

- Even for poles-and-wires utilities, demand-side solutions can reduce utility revenues by reducing the need for rate-based investments in new grid infrastructure.

- Regulated utilities often hold legally protected competitive advantages over third-party service providers, such as protected access to customer data and grid conditions.

- Utility procurement processes are often designed to procure services from specific types of generators and tend to favor conventional centralized assets.

\subsection{Wholesale Market Access}

Several demand-side service business models depend on the ability to sell those services into wholesale electricity markets (Burger and Luke 2017). However, demand-side resources face several barriers in these markets (Gundlach and Webb 2018, Teplin, Dyson et al. 2019):

- Individual demand-side resources are generally prohibited from bidding into wholesale markets.

- Aggregated demand-side resources may be allowed to offer demand response but are prohibited from offering other grid services such as ancillary services. Access rules for aggregated resources vary significantly by market.

- Market rules can force demand-side service providers to choose between mutually exclusive value streams. For instance, in California, DPV participation in demand-side resource aggregation programs precludes systems from participation in net metering programs.

- Market rules were largely designed for large, centralized generators. Design elements that make sense for centralized generation can pose challenges to demand-side resources. For instance, some markets require market participants to report all energy flows, known as $24 / 7$ settlement. Such rules pose challenges to demand-side resources that are designed to provide on-site and grid services, given that energy flows for on-site services count toward 24/7 settlement requirements.

\subsection{Scaling Aggregation}

Aggregation is a critical ingredient for unlocking the full potential of the demand-side opportunity. To date, aggregation has only been implemented in specific niches (e.g., peak demand response) and at relatively small scales (e.g., utility demand-side resource aggregation pilots). Further, even where required, most proposed aggregation projects have failed to move beyond the proposal stage (Menonna and Holden 2020). ${ }^{11}$ Scaling aggregation entails several challenges, including:

\footnotetext{
${ }^{11}$ The study in the citation estimates that only about $40 \%$ of "non-wires alternative" projects moved beyond a proposal stage. Non-wires alternatives are a form of aggregation; however, this particular statistic may not be broadly applicable to all forms of demand-side resource aggregation.
} 
- Aggregating large numbers of demand-side resources: Aggregators need to aggregate hundreds or thousands of individual demand-side resources to effectively compete for grid services (AEIC 2018, Gundlach and Webb 2018, Fallahi and Henze 2019). Early aggregation pilot programs have cited acquisition of a sufficient number of customers as a key challenge (AEIC 2018).

- Building a residential customer value proposition: Many residential customers adopt building energy technologies for their non-energy benefits. Customer participation in aggregation may diminish the customer's ability to realize non-energy values. For instance, battery adopters in an Australian survey stated reluctance to participate in a virtual power plant, reporting that their participation would run counter to their initial reasons for battery adoption (e.g., self-sufficiency) (Roberts, Adams et al. 2020). Aggregators face the challenge of creating enough customer value to offset perceived losses in non-energy benefits.

- Increasing response certainty: Even if aggregators are successful in amassing large numbers of demand-side resources, the value of their services relies on the certainty of the aggregation's response to calls for grid services (Kassakian and Schmalensee 2011, AEIC 2018). For instance, only about half of demand response capacity was available during critical demand peaks in California in 2020 (Maze-Rothstein and Kolo 2020). An enduring perception that demand-side services are less reliable than centralized grid services could pose an ongoing barrier to aggregation (AEIC 2018, Maze-Rothstein and Kolo 2020, Menonna and Holden 2020).

\subsection{Compatibility and Interoperability}

Effective building energy technology coordination and aggregation depend on device-to-device communication. Device-to-device communication, in turn, depends on the ability of devices to interact with networks - known as compatibility - and the ability of multiple devices to interact with each other across networks — known as interoperability. Compatibility and interoperability issues can rise along multiple dimensions (Figure 9): devices may be incompatible with building energy systems, building wireless networks, devices from other manufacturers, or aggregator software (Karlin, Ford et al. 2015, King and Perry 2017, King 2018, Sofos, Langevin et al. 2020). See Sofos et al. (2020) for a comprehensive discussion of interoperability issues. 
Compatibility with Building Energy Systems

Devices may be incompatible with building energy systems (e.g., thermostat incompatibility with building HVAC system)
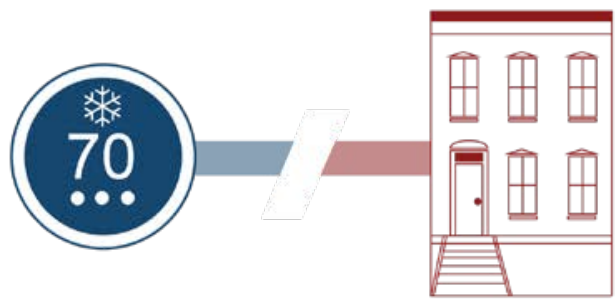

Compatibility with Other Devices

Devices may be incompatible with other devices from other manufacturers using different communication protocols.
Compatibility with Wireless Networks

Devices may be incompatible with building wireless networks. For instance, Zigbee-based devices may be incompatible or interfere with Wi-Fi networks.
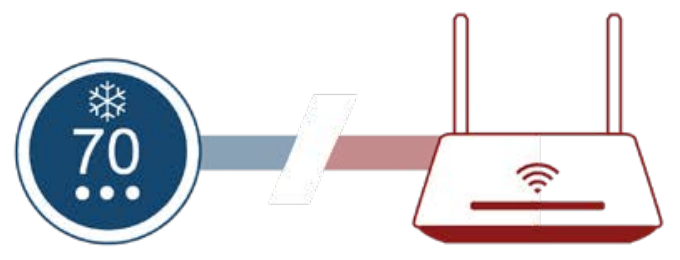

Compatibility with Aggregator Systems Devices may be incompatible with aggregator remote communication systems (e.g., distributed energy resource management systems).

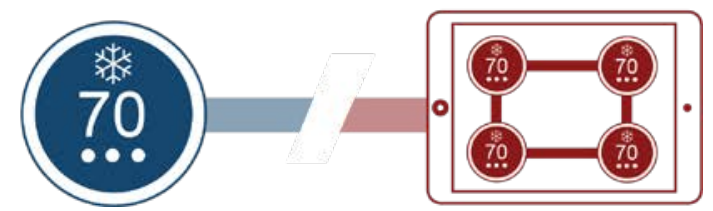

Figure 9. Dimensions of building energy device compatibility and interoperability issues

\subsection{Uncertain Building Occupant Behavior}

All building energy systems require at least some interaction with building managers and occupants, and system-user interactions create a layer of uncertainty for system performance (Hittinger and Jaramillo 2019, Sofos, Langevin et al. 2020). This uncertainty could pose barriers to the demand-side opportunity in at least three ways:

- Noncompliance: Building occupants can interfere with optimized building energy technology settings, particularly in the case of thermostats. Given evidence that building occupant behavior is only weakly responsive to economic signals (Allcott 2011, Ito 2014) and strongly dependent on thermal comfort (Delzendeh, Wu et al. 2017), some degree of noncompliance is likely and potentially significant. For instance, only about $12 \%$ of residential programmable thermostat owners actually use the programmable capacity of their thermostats (Sofos, Langevin et al. 2020).

- Rebound effects: Building energy technology adoption can effectively reduce the per-unit costs of using a given technology. For instance, a lumen of light from an energy-efficient lightbulb is cheaper than from an inefficient bulb. Some building occupants respond to the availability of cheaper per-unit services by using more of those services, a phenomenon known as the rebound effect. Rebound effects could reduce the value of demand-side services by causing users to operate devices in a way that offsets some of the gains. Rebound effects are still poorly understood and require further research (Hittinger and Jaramillo 2019).

- Unexpected technology applications: Building occupants may use technologies in unexpected ways that affect their energy performance or societal acceptability. In a review of these risks, Nicholls et al. (2020) note that smart home device adopters used 
smart devices in a variety of unexpected and undesirable ways, including to precool homes on grid electricity (entailing increased energy use), to surveil family members, and to exacerbate domestic gender imbalances.

\section{Text Box 7. Other barriers}

Other potential barriers to the demand-side opportunity include:

- Permitting, inspection, and interconnection (PII). In the United States, DPV and battery PII requirements vary considerably across permitting jurisdictions and utility service territories. Batteries face distinct PII requirements. PII inconsistency and cumbersome PII rules can increase installation costs, increase installation timelines, and potentially reduce deployment (Dong and Wiser 2013, Burkhardt, Wiser et al. 2015, Bird, Gagnon et al. 2016, Hsu 2018, O'Shaughnessy, Barbose et al. 2020).

- Regulatory uncertainty: Regulatory uncertainty has been a defining feature of demand-side service markets to date. A plethora of utility, market, tax, and permitting rules determine the potential value proposition of demand-side resources (Burger and Luke 2017). These rules are constantly evolving as regulators attempt to keep pace with technological developments.

- Reliance on lithium-ion batteries. Building energy storage relies primarily on lithium-ion batteries. Environmental and social justice concerns associated with battery supply chains-particularly related to lithium and cobalt extraction-could disrupt lithium-ion battery supply chains (Wanger 2011, Romero, Méndez et al. 2012, Lebre, Stringer et al. 2020).

- Limited visibility of demand-side resources. Grid operators have limited visibility into real-time demand-side resource performance (AEIC 2018). This limited visibility reduces the ability of grid operators to optimally integrate demand-side resources into future resource plans (AEIC 2018). 


\section{Potential Game Changers for the Demand- Side Opportunity}

In the near (2020-2030) and long (2030-2050) terms, there are several potential game changers that could shape the role of demand-side resources in future grids. Here, we discuss seven potential game changers, identified with input from a Technical Review Panel of experts (see Acknowledgments). We organize these game changers into opportunities that can be shaped through policies and exogenous shocks.

\subsection{Game-Changing Opportunities}

We identify three game-changing opportunities that can be shaped through proactive policies: large-scale electrification, building energy system orchestration, and technological innovations.

\subsubsection{Large-Scale Electrification}

Large-scale electrification of loads currently met by on-site fuel combustion - especially space and water heating - is being actively discussed as a policy measure for deep decarbonization (Dennis, Colburn et al. 2016, Mahone, Li et al. 2019, Urban Green 2020). Large-scale electrification could add the heating loads of about 70 million buildings to the demand-side resource portfolio (Billimoria, Henchen et al. 2018). The electrification of heating could significantly increase the value proposition of load flexibility by providing a new year-round value stream for water heating and a new winter value stream for space heating (Specian, Cohn et al. 2021). In turn, greater load flexibility could increase the DPV value proposition, driving the deployment of more or larger DPV systems (Rinaldi, Soini et al. 2021).

Policymakers can facilitate large-scale electrification through several policy levers, particularly building codes (see Section 6.2). However, the pace of large-scale electrification is inherently limited by the slow turnover of building infrastructure. Typical space and water heating systems last 10-20 years, meaning that electrification policies implemented in the near term will yield benefits in the long term ( $>10$ years).

\subsubsection{Building Energy System Orchestration}

Demand-side resource coordination and aggregation can occur at multiple levels (Roth 2019). Most commonly, building energy technologies are coordinated within an individual building energy system. Some devices can also be effectively aggregated at the device level, meaning that multiple devices across buildings (e.g., smart thermostats) can be treated as a single load. A third type of coordination co-optimizes technologies across multiple building energy systems. We refer to this type of coordination as building energy system orchestration (Figure 10). 
Flexible loads can be coordinated across building energy systems
Shared assets (e.g., shared batteries)

leverage economies of scale and eliminate redundancies

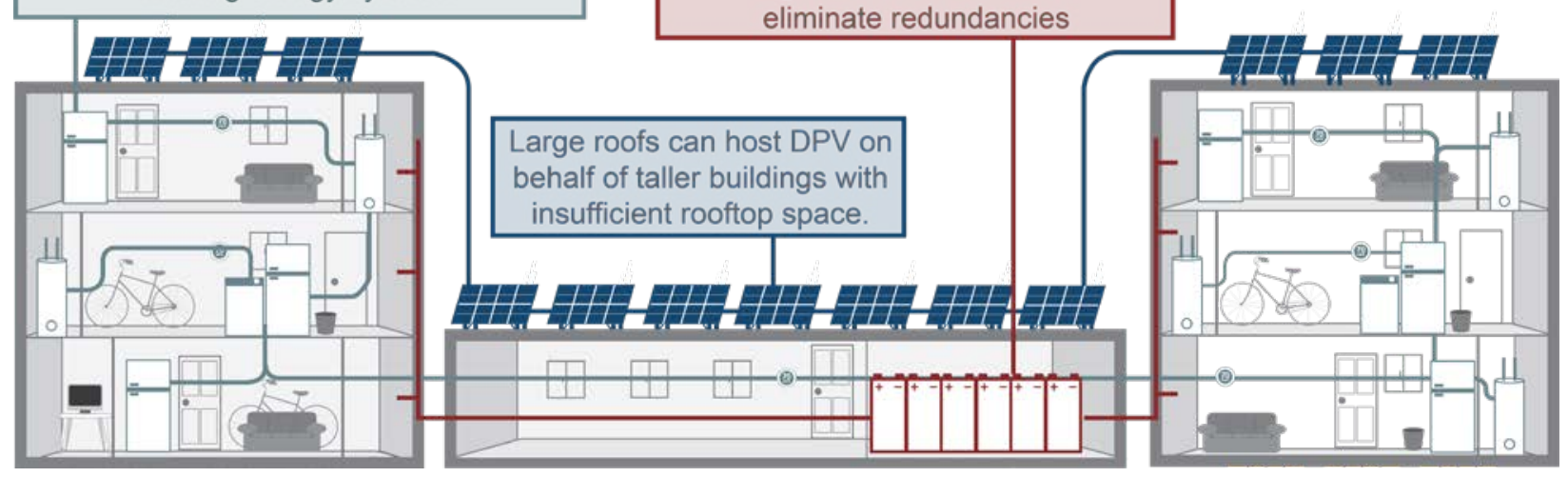

Figure 10. Schematic illustration of building energy system orchestration

Building energy system orchestration is a theoretically game-changing, yet largely untested approach to building energy technology coordination and aggregation. Orchestrated building energy systems could reduce the costs of building energy technology coordination by leveraging economies of scale (Parra, Norman et al. 2017, Parra, Swierczynski et al. 2017). By centralizing and sharing certain equipment across buildings (e.g., batteries, wiring, control systems), orchestration can reduce redundancies associated with installing separate systems in individual buildings (Barbour, Parra et al. 2017, Parra, Swierczynski et al. 2017, Van Der Stelt, AlSkaif et al. 2018, Roberts, Bruce et al. 2019). For instance, one study found that shared batteries could achieve the same results as individually operated batteries, but with 35\% less capacity (Barbour, Parra et al. 2017). Further, orchestration approaches such as shared DPV systems and shared batteries could result in larger system sizes, possibly facilitating orchestrated demand-side resource participation in demand response programs and in wholesale markets.

To demonstrate the potential benefits of orchestration, we modeled building loads for a mall and a hotel on a shared lot using the URBANopt ${ }^{\mathrm{TM}}$ and REopt ${ }^{\mathrm{TM}}$ modeling platforms (see Appendix for modeling details). ${ }^{12}$ We modeled optimal DPV and battery storage system sizes when treating the two buildings as separate systems (unit optimization) and when treating the two buildings as single orchestrated unit (orchestration). To explore the potential implications of differences in building efficiency, we modeled scenarios for standard- and higher-efficiency buildings. Figure 11 illustrates the results of the analysis based on an energy charge $(\$ / \mathrm{kWh})$ rate structure.

\footnotetext{
${ }^{12}$ For more information about URBANopt, see https://www.nrel.gov/buildings/urbanopt.html.
} 

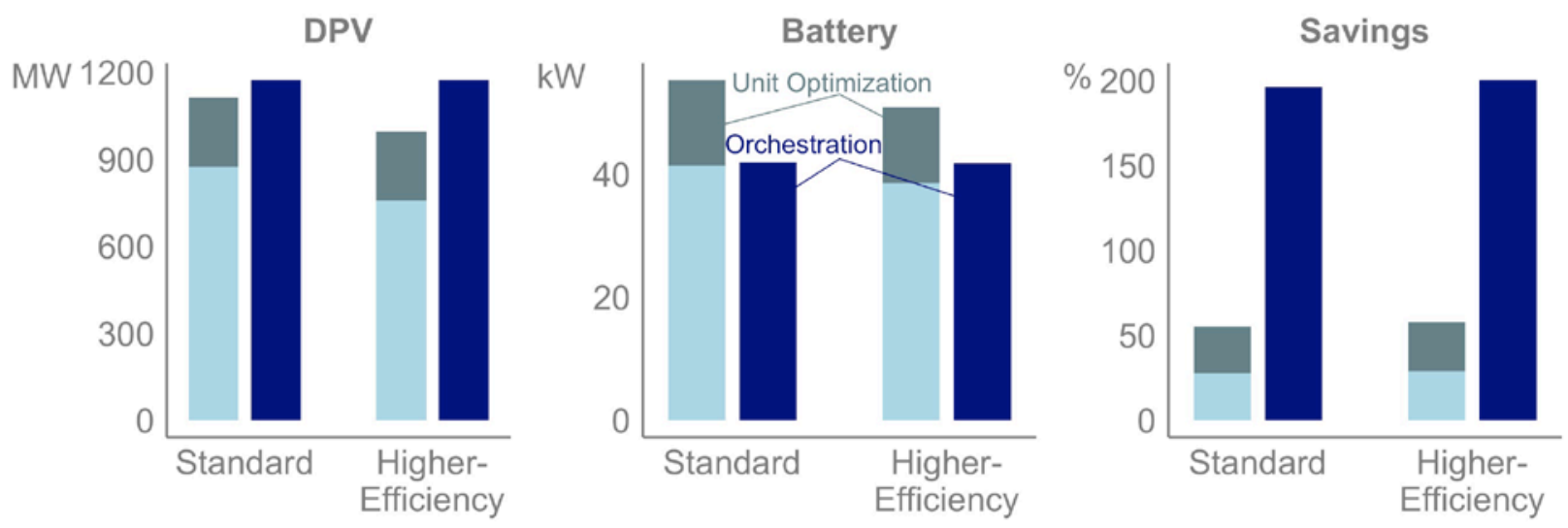

Figure 11. Modeled building energy system orchestration results for optimal DPV system size (left), battery size (center), and cost savings (right)

The results illustrate four key concepts:

- Orchestration results in higher DPV utilization. DPV is under-deployed in the unit optimization scenario because the hotel's hosting capacity is smaller than its need, while the mall's hosting capacity is large enough that some space is left unused. Orchestration corrects this mismatch, allowing the mall to host part of the hotel's DPV system.

- Orchestration results in smaller batteries. Consistent with results from previous studies, we found that orchestration results in more efficient use of battery storage. As a result, orchestration reduces the optimal battery size by about $24 \%$ in the standard-efficiency scenario.

- Orchestration increases the cost savings potential of DPV and batteries. By cooptimizing the building energy technologies, orchestration increases the buildings' electricity cost savings by nearly a factor of four.

- Efficiency increases the effects of orchestration on DPV utilization. The optimal DPV system size for the mall shrinks in the high-efficiency scenario. As a result, the mall has more unused rooftop space in the high-efficiency scenario than in the standard-efficiency scenario. Orchestration puts that unused space to use by allowing the mall to host more of the hotel's optimal DPV system. As a result, orchestration increases the fleet's DPV use by $18 \%$ in the high-efficiency scenario (compared to $5 \%$ in the standard-efficiency scenario).

The results of the orchestration analysis change substantially when assuming a rate structure based primarily on demand charges $(\$ / \mathrm{kW})$. In the unit optimization scenario, the combined total battery capacity was about 10 times greater in the scenarios based on demand charges than in the scenarios based on energy charges, a reflection of the significant demand charge reduction value of batteries. Under the demand charge scenario - unlike under the energy charge scenariosorchestration slightly increased the optimal battery size. DPV is generally less effective at reducing demand charges than at reducing energy charges. As a result, the optimal DPV system size was about $83 \%$ smaller in the demand charge scenario than in the unit optimization energy charge scenario. In the orchestration scenario, batteries can shift loads to reduce demand charges without DPV charging, eliminating the DPV value proposition and driving the optimal DPV 
system size to zero. This outcome reflects the challenges that demand charges can pose to commercial DPV adoption. These results suggest that building energy orchestration could have complex impacts on building energy technology adoption and use that are not yet fully understood. We recommend further research into building energy system orchestration.

\subsubsection{Game-Changing Technological Innovations}

Technological innovations could change the role of building energy technologies in deep decarbonization. Although technological innovations are inherently uncertain, policymakers can support research and development in targeted areas most likely to yield innovations. Two specific technology areas that could yield near-term innovations in DPV and building energy technologies are:

- Building-integrated photovoltaics (BiPV): BiPV refers to DPV systems that serve as, or are integrated into, building envelope materials. Examples of BiPV include PV roofing tiles, PV glazing, PV paints, and PV building materials. By serving a dual purpose as power generators and building envelope materials, BiPV could offer higher value propositions to prospective adopters than rooftop-mounted DPV. Further, BiPV could resolve noneconomic barriers to DPV adoption, such as concerns about aesthetics or impacts on home value. BiPV remains a niche market, in part due to the relatively high costs of BiPV compared to conventional DPV.

- Ground-source heat pump deployment: Ground-source heat pumps leverage constant temperatures below the Earth's surface to extract or store heat. Ground-source heat pumps can heat and cool buildings more efficiently than conventional building heating and cooling systems. By one estimate, equipping all single-family homes with groundsource heat pumps could reduce building heating and cooling emissions by around $45 \%$ (Liu 2010). Significant cost reductions and technological improvements in ground-source heat pumps or other small-scale geothermal systems could create a large role for distributed geothermal systems for deep decarbonization. According to NREL's Electrification Futures Study, the share of residential building space heating powered by heat pumps could grow from around $11 \%$ in 2021 to as much as 59\% by 2050 (Mai et al. 2018).

\subsection{Game-Changing Exogenous Shocks}

Here, we identify four exogenous shocks that could affect the future role of demand-side resources in deep decarbonization.

\subsubsection{Shifts in Building Occupancy and Energy Usage Patterns}

The rise of telecommuting, teleservices, and e-commerce have changed building occupancy patterns. The COVID-19 pandemic accelerated these trends by inducing people to increase their home-based work and services (Sung, Hamilton et al. 2020). These changes in building occupancy patterns will drive changes in building energy usage (Barbour, Cerezo Davila et al. 2019).

In the long term, a reasonable projection is that residential building occupancy will increase and that residential load profiles will be flatter. As residential building occupancy increases, residential demand-side services may become more valuable and may have a larger role to play 
in future grids. Vendors could react to this opportunity by offering new business models to enable residential demand-side services. Further, all else equal, greater residential building energy use should increase incentives to adopt building energy technologies, especially DPV and energy-efficient devices. Finally, increased home energy use shortens the effective lifetime of building energy devices. Accelerated device replacement will, all else equal, increase building energy efficiency as older devices are replaced with newer, more energy-efficient devices (Sung, Hamilton et al. 2020).

Conversely, commercial building occupancy is likely to decline. A key near-term implication of this shift is a net reduction in near-term energy efficiency, given that commercial buildings tend to be more efficient than residential buildings (Sung, Hamilton et al. 2020). In the long term, the implications of changing building occupancy for commercial buildings could be the inverse of the implications described above for residential buildings: commercial building energy managers could face reduced incentives to adopt building energy technologies, and commercial demandside resource capacity could continue to decline (Kellison, Kolo et al. 2020).

Lower commercial building occupancy could exacerbate existing barriers to DPV deployment on commercial buildings (Bird, Gagnon et al. 2016). However, commercial DPV system sizes are often constrained by commercial rooftop space. For instance, healthcare facilities can typically only host DPV systems large enough to offset around $40 \%$ of annual energy use, and supermarkets can only host enough DPV to offset around $20 \%$ of annual energy use (SEIA 2018). As a result, lower commercial building occupancy and utilization rates do not necessarily translate to reduced incentives for DPV adoption.

\subsubsection{Market Concentration in Large ICT Providers}

The large-scale conversion of building devices to smart devices could reshape multiple industries. Device manufacturers may become increasingly reliant on software companies and ICT supply chains (Porter and Heppelmann 2014). For some devices, the software-embedded smart capabilities could comprise more marginal value than the underlying physical device (Porter and Heppelmann 2014). Comparable to other industries (e.g., smartphones), the emerging interdependence of the device and software industries could drive the smart device market to concentrate in a few large ICT companies, such as Google, Amazon, AT\&T, and Apple (Porter and Heppelmann 2014).

Market concentration in large ICT companies could have several game-changing implications for the role of demand-side resources in future grids, including:

- Horizontal integration of smart devices: Conventional device manufacturers have already developed packages of smart devices that can be easily integrated based on shared protocols. In the future, ICT vendors may take a similar approach to develop comprehensive smart building packages. Smart building packages could include DPV, allowing for seamless DPV system optimization through flexible loads and batteries. Such packages could improve user experiences by creating common protocols and user interfaces across all smart building devices. 
- Vertical integration of hardware, software, and services: Several large ICT companies can develop hardware and software as well as providing ongoing services to support device users. Vertical integration could allow ICT companies to provide building energy management as a service.

- Device interoperability issues: Market concentration could exacerbate the device interoperability issues discussed in Section 4.5. DPV inverter manufacturers could respond by manufacturing inverters with specific communication protocols to integrate with other smart devices developed by large vendors.

- Market power: Significant market concentration could allow a small number of large ICT companies to accumulate market power. In turn, sustained market power could result in higher prices for building energy technologies.

\subsubsection{Climate Change}

Climate change could shape the role of demand-side resources in future grids. Climate change projections are inherently uncertain, but a few plausible impacts of climate change on the role of demand-side resources include:

- More volatile weather patterns could translate to more volatile electricity demand, increasing the value of load flexibility (Auffhammer, Baylis et al. 2017).

- Warmer weather could increase demand for air conditioning which, all else equal, would increase building electricity demands overall. Already, demographic shifts to warmer climates have driven recent increases in building electricity demand (EIA 2020). Given the generally strong correlation between DPV output profiles and temperature, warmer weather could increase the DPV value proposition.

- Conversely, extreme cold events (e.g., polar vortexes) could result in "peakier" demand in cold regions with electrified heating. Winter peaks would increase the value of flexible heating loads.

- Climate-related natural disasters could catalyze interest in demand-side resources.

Disasters that cause grid outages - such as tropical storms and wildfires - can increase adoption of DPV and batteries for backup power. For instance, traffic on a DPV quote website increased by a factor of three during the week of widespread power outages in Texas (Carpenter 2021).

- Increasing wildfire and storm risks could deter future investments in transmission network expansions, increasing the value of demand-side resources relative to centralized grid assets.

- Changing climate patterns could translate to demographic shifts. For instance, extreme heat or wildfires could drive people to migrate from the Southwest to the Midwest, effectively increasing the need for building heating and reducing air-conditioning loads, at least in the near term. 


\subsubsection{Grid Resiliency Events}

Grid shocks from natural disasters could spark interest in demand-side resources as resiliency assets. On the other hand, cybersecurity and privacy concerns have posed barriers to the beneficial adoption of certain building energy technologies (King and Perry 2017, Nicholls, Strengers et al. 2020). Even a single grid cybersecurity breach could stoke cybersecurity concerns and deter the beneficial adoption of grid-connected building energy technologies. Further, the distributed nature of building energy technologies could make these technologies vulnerable entry points for grid cybersecurity attacks (Powell, Hauck et al. 2019). A cybersecurity breach of a building energy technology could undermine societal and political acceptability of demand-side resources. 


\section{Policy Pathways}

Buildings and demand-side resources are governed by a wide array of policies and regulations at multiple jurisdictional levels. Within these jurisdictional levels, there are numerous potential policy and regulatory reforms that could optimize the role of buildings in future grids. For simplicity, we organize these potential reforms into three pathways:

- An energy policy pathway, which uses existing energy policy and regulatory frameworks to incentivize the beneficial adoption and use of building energy technologies

- A building policy pathway, which uses existing building policies to incentivize or require the beneficial adoption and use of building energy technologies

- A building user pathway, which uses behavioral interventions to "nudge" user decisionmaking toward adopting beneficial building technologies.

\subsection{Energy Policy Pathway}

Energy policy is mostly set at the state level through state agencies and public utility commissions. Utilities are the primary implementers of state energy policies. The key state-level energy policy levers are utility rate and business model reform (Section 6.1.1). The federal government plays a limited role in building energy policy, except in the case of wholesale electricity markets, which fall under the jurisdiction of the U.S. Federal Energy Regulatory Commission (Section 6.1.2).

\subsubsection{Utility Rate and Business Model Reform}

Electricity rate structures are the key determinants of the potential electricity cost savings from building energy technology investments (O'Shaughnessy, Cutler et al. 2018, Hledik, Faruqui et al. 2019). Regulators can use the rate-making process to incentivize beneficial adoption of demand-side resources and the use of those resources to provide demand-side services. The challenges of rate reform notwithstanding (see Section 4.2), many U.S. states and utilities have already begun to modify rate structures in response to the rise of demand-side resources (Burns, Bialecki et al. 2020). Common rate reforms include moving more customers onto mandatory time-of-use or demand charge rates that incentivize load shifting and peak reduction (Burns, Bialecki et al. 2020). In 2019, around 10 million retail electricity customers were enrolled in some form of time-variant rate structure (Burns, Bialecki et al. 2020). A few states and utilities have created more complex rates designed specifically for DPV adopters (Rábago and Valova 2018, O’Shaughnessy and Ardani 2020).

One key challenge in rate design is ensuring that any cost shifts between customers are just and reasonable (Rule 2015). Cost shifting is an inevitable outcome of a highly complex system of rates designed to recoup system costs from thousands of individual customers. The emergence of demand-side resources presents the possibility of cost shifts from demand-side resource adopters to nonadopters. Some degree of cost shifting between adopters may be just and reasonable if it motivates the beneficial adoption and use of demand-side resources. However, given that nonadopters tend to be lower-income households, these cost shifts pose energy justice concerns. Rate designers could explore specific measures to address inequitable cost shifting while maintaining the value proposition for demand-side resources and services (Revesz and Unel 2017). 
Conventional utility business models pose a barrier to large-scale demand-side resource utilization (see Section 4.2, Text Box 6). Conversely, the large-scale proliferation of building energy technologies could undermine conventional utility business models (Corneli and Kihm 2015). Hence, utility business model reforms can be both a proactive measure to optimize the value of demand-side services as well as a reactive measure to adapt utility responsibilities to the changing realities of electric grids. Several utility business model reforms have been proposedand in some cases, implemented - to increase the contribution of demand-side services to grid transformation. These proposed reforms include:

- Utility-owned building energy technologies: Utilities could own building-sited assets such as DPV and batteries while leasing building spaces. Utility ownership faces numerous challenges, and the benefits of utility ownership remain unclear, but early research suggests that well-designed programs could drive beneficial adoption and use of building energy technologies (Barbose and Satchwell 2020).

- Third-party competition: Third-party vendors could be allowed to compete directly with utilities to provide demand-side services. This model would require measures to ensure that utilities do no hold unfair competitive advantages over third-party vendors.

- Third-party provision: Utilities could be required to contract with third-party vendors of demand-side services. Alternatively, utilities could be prohibited from competing with third-party vendors, except in specific cases where third-party services are unlikely to materialize, such as services for low- and moderate-income communities.

- Utility-hosted platforms: Utilities could be required to host a transactive local marketplace, allowing for peer-to-peer exchanges of demand-side services.

- All-source procurement: Utility solicitations could be designed to address specific grid needs that can be met by any source-including demand-side services.

- Utility pilots: Utilities could partner with vendors and contractors to roll out new products (King 2018). For instance, several utilities are piloting management systems for demandside resource aggregation (Cook, Ardani et al. 2018).

See Corneli and Kihm (2015) and Cross-Call et al. (2018) for more comprehensive discussions of utility business model reform.

\subsubsection{Wholesale Market Reform}

Wholesale electricity market rules have largely restricted demand-side resource participation (see Section 4.3). At a minimum, market designers could reform markets to allow demand-side resources to compete alongside conventional centralized grid assets (Teplin, Dyson et al. 2019). Potential market reforms include:

- Expanding demand-side service offerings: The Federal Energy Regulatory Commission and market designers could further expand the scope of services for which demand-side resources are allowed to compete.

- Creating unique rules for demand-side resource participation: Market designers could reexamine existing rules designed for large-scale generators and modify those rules according to the distinct characteristics of demand-side resources. For instance, market 
designers could explore ways to relax $24 / 7$ settlement requirements for resources that provide a mix of on-site and grid services (see Section 4.4).

- Eliminating unnecessary costs: Market designers could waive certain market access requirements for small-scale demand-side resources, such as requirements for revenuegrade meters.

- Allowing participation in multiple programs: Policymakers could reform rules that restrict demand-side service providers to offering a single value stream, such as rules that prohibit net-metered DPV systems from participating in demand-side resource aggregation programs.

\subsection{Building Policy Pathway}

Building policies are mostly set at the state level through building energy codes. Local authorities (e.g., city, county) are generally the primary implementers of building policies and, in some cases, may have the authority to implement stricter policies than required by the state. Building energy codes are projected to save over $\$ 100$ billion in energy costs and avoid around 800 million tons of $\mathrm{CO}_{2}$ from 2010 to 2040 (Athalye, Liu et al. 2016). An expansion of building energy codes could increase these benefits (Nadel and Ungar 2019). Building energy codes could expand the role of buildings in future grids in several ways, including through:

- Technology-ready requirements and technology mandates: Codes could require buildings to be equipped with infrastructure to facilitate technology installation, such as DPV-ready rooftops. Codes could also require buildings to be equipped with specific technologies (Cortese and Lyles 2020).

- Electrification: Codes could incentivize electrified systems (e.g., heating) or specifically prohibit fuel-based infrastructure (Kerr and Platt 2020).

- Increased standards for building thermal performance: Increased building thermal performance can increase load flexibility potential. For instance, better-insulated buildings with high thermal mass can more effectively "store" heat or cool air, increasing their capacity to preheat or precool with DPV output.

- Time-dependent valuation: Codes could incentivize building designs that yield energy benefits at specific times, particularly during peak periods.

- Emissions efficiency: Building codes could score building energy technologies based on emissions efficiency rather than energy efficiency. Emissions efficiency measures the annual emissions abatement potential of an energy efficiency or other building energy design element, rather than the annual energy abatement potential (Dennis, Colburn et al. 2016).

- Increased enforcement: Enforcement and monitoring can be designed explicitly into building codes through outcome-based standards (Cortese and Lyles 2020). For instance, code authorities could hold deposits until buildings are able to demonstrate code compliance (Cortese and Lyles 2020).

- Emissions standards: Building energy codes could place explicit caps on building carbon emissions. For instance, New York City's building codes include a provision to reduce building emissions by $40 \%$ by 2030 . 
- Building energy benchmarking: Over 30 cities in the United States require large commercial buildings to report key energy metrics to building energy benchmarking programs (IMT 2019). Building energy benchmarking programs can help building energy managers and building authorities identify inefficient buildings and prioritize those buildings for technology retrofits.

Building energy technology standards are a second key policy lever in the building policy pathway. Many building devices must comply with federal appliance efficiency standards, and voluntary federal programs such as ENERGY STAR ${ }^{\circledR}$ recognize outstanding efficiency performance. By one estimate, an expansion of appliance efficiency standards and voluntary programs could reduce building emissions by around 13\% (Nadel and Ungar 2019). Another type of technology standard involves protocols to address technology interoperability issues (see Section 4.5). See Sofos et al. (2020) for a review of emerging communication standards. The federal government could support the research and development of such standards, and state governments could support standardization by integrating protocols into building energy codes and other state building energy programs.

\subsection{Building User Pathway}

Building energy use is ultimately designed for, and determined by, individual decision makers. This final policy pathway comprises behavioral interventions that can yield beneficial building energy technology adoption and use behavior. Behavioral nudges could provide relatively lowcost but effective ways to encourage optimal building energy technology adoption and energy use decision-making. Potential nudges include:

- Leveraging peer effects: Individuals are more likely to adopt technologies when they interact with peers that have done so themselves, a phenomenon known as peer effects (Wolske, Gillingham et al. 2020). Policymakers could leverage peer effects by designing policies to maximize beneficial peer influence, such as incentives that support technology adoption by prominent community figures (e.g., rooftop DPV installations on salient church rooftops). Augmenting these peer effects may be particularly important in lowand moderate-income neighborhoods that have been historically underserved in building energy technology markets (Wolske, Gillingham et al. 2020).

- Defaults: Research shows that people tend to make decisions based on the default choice in a set of options. Policymakers could leverage default bias in building energy policy design by requiring beneficial defaults in building energy technologies. For instance, smart thermostat defaults could be required to vary according to local grid needs.

- Opt-out design: Like the concept of default bias, social science research shows that individuals are more likely to participate in a voluntary program when they are required to opt out of, rather than into, participation. Opt-out design could increase beneficial participation in voluntary programs such as utility load flexibility and demand-side resource aggregation programs. Voluntary renewable energy programs provide an example of the power of opt-out design. Participation in opt-in voluntary renewable 
energy programs is typically below $5 \%$, but participation in opt-out programs is generally over $80 \%{ }^{13}$

- Social norms design: Research shows that individuals respond strongly to nudges that force them to compare their own behavior to that of peers. Social norms design can be incorporated into building energy policies. For instance, building energy benchmarking programs can publish performance data to encourage beneficial competition among program participants.

- Design for non-energy benefits: Given that non-energy benefits can affect technology adoption as much or more than energy benefits, building energy programs could emphasize non-energy benefits in program marketing materials.

${ }^{13}$ Based on comparisons of participation rates in opt-in utility programs versus opt-out community choice aggregation programs. 


\section{Conclusion}

Building energy systems can provide potentially valuable demand-side grid services that are currently underutilized. Through a literature review supplemented by NREL modeling, we found that leveraging underutilized demand-side resources presents a significant opportunity to transform and decarbonize grids more quickly and cost-effectively. Demand-side resources can complement supply-side solutions to deep decarbonization by reducing grid net loads (lowering the bar) and enhancing grid flexibility. The potential benefits of building energy technologies are generally on the order of $20 \%$ (e.g., $20 \%$ increase in output, $20 \%$ reduction in demand, $20 \%$ reduction in costs). This heuristic provides a reasonable first-order approximation of the size of the demand-side opportunity, though game-changing trends and policies could yield an even larger role for demand-side resources in deep decarbonization.

Recent ICT advances have significantly enhanced building technology automation and coordination capabilities. Effectively coordinated building energy systems can enhance the value of demand-side services by exploiting synergies between building energy technologies and DPV. For instance, effectively coordinated flexible loads and energy storage can reshape building load profiles to optimize the on-site use of DPV. Further, ICT advances have significantly improved demand-side resource aggregation capabilities. Emerging business models, such as virtual power plants, leverage advanced communication capabilities to effectively aggregate hundreds or thousands of building energy technologies to provide grid services.

Several barriers to the demand-side opportunity remain, and several game-changing trends could fundamentally disrupt the role of demand-side resources in deep decarbonization. Notwithstanding these barriers and potential disruptions, demand-side resources could play a key role in grid transformation and deep decarbonization. Policymakers could maximize the contribution of demand-side resources to deep decarbonization by exploring energy and building policy levers that mitigate the remaining barriers to the demand-side opportunity. 


\section{References}

AEIC (2018). Enabling Smart Inverters for Distribution Grid Services, The Association of Edison Illuminating Companies.

Allcott, H. (2011). "Rethinking real-time electricity pricing." Resource and Energy Economics 33(4): 820-842.

Athalye, R. A., B. Liu, D. Sivaraman, R. Bartlett and D. B. Elliott (2016). Impacts of Model Building Energy Codes, Pacific Northwest National Laboratory.

Auffhammer, M., P. Baylis and C. Hausman (2017). "Climate change is projected to have severe impacts on the frequency and intensity of peak electricity demand across the United States." Proceedings of the National Academy of Sciences 114(8): 1886-1891.

Baker, S. (2021). Revolutionary Power. Washington, DC, Island Press.

Barbose, G., N. Darghouth, E. O'Shaughnessy and S. Forrester (2020). Distributed Solar 2020 Data Update. Berkeley, CA, Lawrence Berkeley National Laboratory.

Barbose, G., S. Forrester, N. Darghouth and B. Hoen (2020). Income Trends among U.S. Residential Rooftop Solar Adopters. Berkeley, CA, Lawrence Berkeley National Laboratory.

Barbose, G. and A. Satchwell (2020). "Benefits and costs of a utility-ownership business model for residential rooftop solar photovoltaics." Nature Energy 5: 750-758.

Barbour, E., C. Cerezo Davila, S. Gupta, C. Reinhart, J. Kaur and M. González (2019).

"Planning for sustainable cities by estimating building occupancy with mobile phones." Nature Communications 10: 3736.

Barbour, E., D. Parra, Z. Awwad and M. González (2017). "Community energy storage: A smart choice for the smart grid?" Applied Energy 212: 489-497.

Billimoria, S., M. Henchen, L. Guccione and L. Louis-Prescott (2018). The Economics of Electrifying Buildings: How Electric Space and Water Heating Supports Decarbonization of Residential Buildings. Boulder, CO, Rocky Mountain Institute.

Bird, L., P. Gagnon and J. Heeter (2016). Expanding Midscale Solar: Examining the Economic Potential, Barriers, and Opportunities at Offices, Hotels, Warehouses, and Universities. Golden, $\mathrm{CO}$, National Renewable Energy Laboratory.

Bonbright, J. (1961). Principles of Public Utility Rates. New York, Columbia University Press.

Brown, M., A. Soni, M. Lapsa and K. Southworth (2020). Low-Income Energy Affordability: Conclusions from a Literature Review, Oak Ridge National Laboratory.

Burger, S., J. Jenkins, S. Huntington and I. Pérez-Arriaga (2019). "Why Distributed? A Critical Review of the Tradeoffs Between Centralized and Decentralized Resources." IEEE Power \& Energy Magazine. 
Burger, S. P. and M. Luke (2017). "Business models for distributed energy resources: A review and empirical analysis." Energy Policy 109: 230-248.

Burkhardt, J., R. Wiser, N. Darghouth, C. G. Dong and J. Huneycutt (2015). "Exploring the impact of permitting and local regulatory processes on residential solar prices in the United States." Energy Policy 78: 102-112.

Burns, D., T. Bialecki, G. Gil, D. Kathan, M. P. Lee, S. Peirovi and R. Puram (2020). 2020 Assessment of Demand Response and Advanced Metering, Federal Energy Regulatory Commission.

Carpenter, S. (2021). Traffic To Rooftop Solar Websites Surges As Texans Seek Freedom From Grid. Forbes.

Clack, C., A. Choukulkar, B. Coté and S. McKee (2020). Why Local Solar For All Costs Less: A New Roadmap for the Lowest Cost Grid. Boulder, CO, Vibrant Clean Energy.

Cole, W. J., D. Greer, P. Denholm, A. W. Frazier, S. Machen, T. Mai, N. Vincent and S. F. Baldwin (2021). "Quantifying the challenge of reaching a 100\% renewable energy power system for the United States." Joule 5: 1-17.

Cook, J., K. Ardani, E. O'Shaughnessy and R. Margolis (2018). Expanding PV Value: Lessons Learned from Utility-led Distributed Energy Resource Aggregation in the United States. Golden, CO, National Renewable Energy Laboratory.

Corneli, S. and S. Kihm (2015). Electric Industry Structure and Regulatory Responses in a High Distributed Energy Resources Future, Lawrence Berkeley National Laboratory.

Cortese, A. and M. Lyles (2020). Energy Code Roadmaps for Getting to Zero Outcomes. Portland, OR, New Buildings Institute.

Cross-Call, D., R. Gold, L. Guccione, M. Henchen and V. Lacy (2018). Reimagining the Utility: Evolving the Functions and Business Model of Utilities to Achieve a Low-Carbon Grid. Boulder, CO, Rocky Mountain Institute.

Dale, V., R. Efroymson and K. Kline (2011). "The land use-climate change-energy nexus." Landscape Ecology 26(6): 755-773.

Delzendeh, E., S. Wu, A. Lee and Y. Zhou (2017). "The impact of occupants' behaviours on building energy analysis: A research review." Renewable \& Sustainable Energy Reviews 80: 1061-1071.

Denholm, P., D. J. Arent, S. F. Baldwin, D. E. Bilello, G. L. Brinkman, J. M. Cochran, W. J. Cole, B. Frew, V. Gevorgian, J. Heeter, B.-M. S. Hodge, B. Kroposki, T. Mai, M. O’Malley, B. Palmintier, D. Steinberg and Y. Zhang (2021). "The challenges of achieving a 100\% renewable electricity system in the United States." Joule 5: 1-22. 
Dennis, K., K. Colburn and J. Lazar (2016). "Environmentally beneficial electrification: The dawn of 'emissions efficiency'." The Electricity Journal 29: 52-58.

Dong, C. and R. Wiser (2013). "The impact of city-level permitting processes on residential photovoltaic installation prices and development times: An empirical analysis of solar systems in California cities." Energy Policy 63: 531-542.

Dyson, M., J. Mandel, P. Bronski, M. Lehrman, J. Morris, T. Palazzi, S. Ramirez and H. Touati (2015). The Economics of Demand Flexibility. Boulder, CO, Rocky Mountain Institute.

Eckman, T., L. Schwartz and G. Leventis (2020). Determining Utility System Value of Demand Flexibility. Berkeley, CA, Lawrence Berkeley National Laboratory.

EIA (2020). Annual Energy Outlook 2020. Washington, DC, Energy Information Administration.

EIA (2021). Annual Energy Outlook 2021, U.S. Energy Information Administration.

Fallahi, Z. and G. Henze (2019). "Interactive Buildings: A Review." Sustainability 11: 3988.

Fares, R. and M. Webber (2017). "The impacts of storing solar energy in the home to reduce reliance on the utility." Nature Energy 2(17001).

Fernandez, N., S. Katipamula, W. Wang, Y. Xie, M. Zhao and C. Corbin (2017). Impacts of Commercial Building Controls on Energy Savings and Peak Load Reduction. Richland, WA, Pacific Northwest National Laboratory.

Gagnon, P., R. Margolis, J. Melius, C. Phillips and R. Elmore (2016). Rooftop Solar Photovoltaic Technical Potential in the United States: A Detailed Assessment. Golden, CO, NREL.

Goldenberg, C., M. Dyson and H. Masters (2018). Demand Flexibility: The Key to Enabling a Low-Cost, Low-Carbon Grid, Rocky Mountain Institute.

Gundlach, J. and R. Webb (2018). "Distributed energy resource participation in wholesale markets: Lessons from the California ISO." Energy Law Journal.

Gupta, R., A. Pena-Bello, K. Nino Streicher, C. Roduner, Y. Farhat, D. Thöni, M. Kumar Patel and D. Parra (2021). "Spatial analysis of distribution grid capacity and costs to enable massive deployment of PV, electric mobility and electric heating." Applied Energy 287: 116504.

Hernandez, R. R., S. B. Easter, M. L. Murphy-Mariscal, F. T. Maestre, M. Tavassoli, E. B. Allen, C. W. Barroes, J. Belnap, E. Ochoa-Hueso, S. Ravi and M. F. Allen (2014).

"Environmental impacts of utility-scale solar energy." Renewable \& Sustainable Energy Reviews 29: 766-779.

Hernandez, R. R., M. K. Hoffacker and C. B. Field (2015). "Efficient use of land to meet sustainable energy needs." Nature Climate Change 5: 353-358. 
Hirsch, A., Y. Parag and J. Guerrero (2018). "Microgrids: A review of technologies, key drivers, and outstanding issues." Renewable \& Sustainable Energy Reviews 90: 402-411.

Hittinger, E. and P. Jaramillo (2019). "Internet of Things: Energy boon or bane?" Science 364: 326-328.

Hledik, R., A. Faruqui, T. Lee and J. Higham (2019). The National Potential for Load Flexibility, The Brattle Group.

Hockenos, P. (2020). As Big Energy Gains, Can Europe's Community Renewables Compete? Yale Environment 360.

Holden, C., G. Curtin, G. Gupta, D. Finn-Foley, A. Perea and R. Manghani (2020). U.S. Energy Storage Monitor Q4 2020, Wood Mackenzie Power \& Renewables/U.S. Energy Storage Association.

Horowitz, K., Z. Peterson, M. Coddington, F. Ding, B. Sigrin, D. Saleem, S. E. Baldwin, B. Lydic, S. C. Stanfield, N. Enbar, S. Coley, A. Sundararajan and C. Schroeder (2019). An Overivew of Distributed Energy Resource (DER) Interconnection: Current Practices and Emerging Solutions. Golden, CO, National Renewable Energy Laboratory.

Hsu, J. H.-Y. (2018). "Predictors for adoption of local solar approval processes and impact on residential solar installations in California cities." Energy Policy 117: 463-472.

IMT (2019). Using Monthly Energy Data from Benchmarking Programs, Institute for Market Transformation.

Ito, K. (2014). "Do consumers respond to marginal or average price? Evidence from nonlinear electricity pricing." American Economic Review 104(2): 537-563.

Jenkins, J., M. Luke and S. Thernstrom (2018). "Getting to Zero Carbon Emissions in the Electric Power Sector." Joule 2: 2498-2510.

Joskow, P. (2019). "Challenges for wholesale electricity markets with intermittent renewable generation at scale: the US experience." Oxford Review of Economic Policy 35(2): 291-331.

Jungclaus, M., C. Carmichael and P. Keuhn (2019). Value Potential for Grid-Interactive Efficient Buildings in the GSA Portfolio: A Cost-Benefit Analysis, Rocky Mountain Institute.

Karlin, B., R. Ford, A. Sanguinetti, C. Squiers, J. Gannon, M. Rajukumar and K. Donnelly (2015). Characterization and Potential of Home Energy Management (HEM) Technology, Pacific Gas \& Electric Company.

Kassakian, J. and R. Schmalensee (2011). The Future of the Electric Grid, MIT.

Kellison, B., E. Kolo, I. Maze-Rothstein, R. Manghani, K. McCoy, F. Menonna, B. Simon and F. Wang (2020). United States distributed energy resources outlook: DER installations and forecasts 2016-2020E, Wood Mackenzie. 
Kerr, L. and R. Platt (2020). Accelerating Deep Decarbonization in the U.S. Buildings Sector. America's Zero Carbon Action Plan. E. Crete, Sustainable Development Solutions Network: 237-261.

King, J. (2018). Energy Impacts of Smart Home Technologies. Washington, DC, ACEEE.

King, J. and C. Perry (2017). Smart Buildings: Using Smart Technology to Save Energy in Existing Buildings. Washington, DC, ACEEE.

Langevin, J., C. B. Harris and J. L. Reyna (2019). "Assessing the Potential to Reduce U.S. Building CO2 Emissions $80 \%$ by 2050." Joule 3: 1-22.

Larsen, J. and W. Herndon (2017). What is it Worth? The State of the Art in Valuing Distributed Energy Resources. New York, NY, Rhodium Group.

Larson, E., C. Greig, J. Jenkins, E. Mayfield, A. Pascale, C. Zhang, J. Drossman, R. Williams, S. Pacala, R. Socolow, E. Baik, R. Birdsey, R. Duke, R. Jones, B. Haley, E. Leslie, K. Paustian and A. Swan (2020). Net-Zero America: Potential Pathways, Infrastructure, and Impacts, interim report. Princeton, NJ, Princeton University.

Lebre, É., M. Stringer, K. Svobodova, J. R. Owen, D. Kemp, C. Côte, A. Arratia-Solar and R. K. Valenta (2020). "The social and environmental complexities of extracting energy transition metals." Nature Communications 11: 4823.

Liu, X. (2010). Assessment of National Benefits from Retrofitting Existing Single-Family Homes with Ground Source Heat Pump Systems, Resources for the Future.

Mahone, A., C. Li, Z. Subin, M. Sontag, G. Mantegna, A. Karolides, A. German and P. Morris (2019). Residential Building Electrification in California. San Francisco, CA, Energy and Environmental Economics.

Mai, T., P. Jadun, J. Logan, C. McMillan, M. Muratori, D. Steinberg, L. Vimmerstedt, R. Jones, B. Haley and B. Nelson (2018). Electrification Futures Study: Scenarios of Electric Technology Adoption and Power Consumption for the United States. Golden, CO, National Renewable Energy Laboratory.

Masson, V., M. Bonhomme, J.-L. Salagnac, X. Brottet and A. Lemonsu (2014). "Solar panels reduce both global warming and urban heat island." Frontiers in Environmental Science 2(14): 110.

Maze-Rothstein, I. and E. Kolo (2020). Market design, DERs and the future of flexibility, Wood Mackenzie.

Menonna, F. and C. Holden (2020). Where Are All the Non-Wires Alternatives? Greentech Media.

Mims Frick, N., S. Price, L. Schwartz, N. Hanus and B. Shapiro (2021). Locational Value of Distributed Energy Resources. Lawrence Berkeley National Laboratory. 
Morstyn, T., N. Farrell, S. J. Darby and M. D. McCulloch (2018). "Using peer-to-peer energytrading platforms to incentivize prosumers to form federated power plants." Nature Energy 3(2): 94-101.

Nadel, S., N. Elliott and T. Langer (2015). Energy Efficiency in the United States: 35 Years and Counting. Washington, DC, ACEEE.

Nadel, S. and L. Ungar (2019). Halfway There: Energy Efficiency Can Cut Energy Use and Greenhouse Gas Emissions in Half by 2050. Washington, DC, ACEEE.

NBI (2020). A Review of the Onsite Renewable Utilization Efficiency Metric, New Buildings Institute.

Neukomm, M., V. Nubbe and R. Fares (2019). Grid-interactive Efficient Buildings Technical Report Series: Overview of Research Challenges and Gaps, U.S. Department of Energy.

Nicholls, L., Y. Strengers and J. Sadowski (2020). "Social impacts and control in the smart home." Nature Energy 5(3): 180-182.

O'Shaughnessy, E., G. Barbose and R. Wiser (2020). "Patience is a virtue: A data-driven analysis of rooftop solar PV permitting timelines in the United States." Energy Policy 144: 111615.

O'Shaughnessy, E., D. Cutler, K. Ardani and R. Margolis (2018). "Solar plus: A review of the end-user economics of solar PV integration with storage and load control in residential buildings." Applied Energy 228: 2165-2175.

Ong, S., C. Campbell, P. Denhom, R. Margolis and G. Heath (2013). Land-Use Requirements for Solar Power Plants in the United States. Golden, CO, National Renewable Energy Laboratory.

O’Shaughnessy, E. and K. Ardani (2020). "Distributed rate design: A review of early approaches and practical considerations for value of solar tariffs." The Electricity Journal 33(3): 106713.

Parra, D., S. Norman, G. Walker and M. Gillott (2017). "Optimum community energy storage for renewable energy and demand load management." Applied Energy 200: 358-369.

Parra, D., M. Swierczynski, D. Stroe, S. Norman, A. Abdon, J. Worlitschek, T. O'Doherty, L. Rodrigues, M. Gillott, X. Zhang, C. Bauer and M. Patel (2017). "An interdisciplinary review of energy storage for communities: Challenges and perspectives." Renewable and Sustainable Energy Reviews 79: 730-749.

Porter, M. and J. Heppelmann (2014). How Smart, Connected Products Are Transforming Competition. Harvard Business Review.

Powell, C., K. Hauck, A. Sanghvi, A. Hasandka, J. Van Natta and R. Tami (2019). Guide to the Distributed Energy Resources Cybersecurity Framework. Golden, CO, National Renewable Energy Laboratory. 
Powells, G. and M. J. Fell (2019). "Flexibility capital and flexibility justice in smart energy systems." Energy Research \& Social Science 54: 56-59.

Prasanna, A., K. McCabe, B. Sigrin and N. Blair (2021). Storage Futures Study Distributed Solar and Storage Outlook: Methodology and Scenarios. Golden, CO, National Renewable Energy Laboratory.

Revesz, R. L. and B. Unel (2017). "Managing the Future of the Electricity Grid: Distributed Generation and Net Metering." Harvard Environmental Law Review 41: 43-108.

Rinaldi, A., M. C. Soini, K. Streicher, M. K. Patel and D. Parra (2021). "Decarbonising heat with optimal PV and storage investments: A detailed sector coupling modelling framework with flexible heat pump operation." Applied Energy 282: 116110.

Roberts, M., S. Adams and D. Kuch (2020). VPP User Research, Solar Analytics.

Roberts, M., A. Bruce and I. MacGill (2019). "Impact of shared battery energy storage systems on photovoltaic self-consumption and electricity bills in apartment buildings." Applied Energy 245: 78-95.

Romero, H., M. Méndez and P. Smith (2012). "Mining Development and Environmental Injustice in the Atacama Desert of Northern Chile." Environmental Justice 5(2): 70-76.

Roth, A. (2019). Grid-interactive Efficient Buildings Technical Report Series: Whole-Building Controls, Sensors, Modeling, and Analytics, U.S. Department of Energy.

Rule, T. A. (2015). "Solar Energy, Utilities, and Fairness." San Diego Journal of Climate \& Energy Law 6: 115-148.

Russell, C., B. Baatz, R. Cluett and J. Amann (2015). Recognizing the Value of Energy Efficiency's Multiple Benefits. Washington, DC, ACEEE.

Rábago, K. and R. Valova (2018). "Revisiting Bonbright's principles of public utility rates in a DER world." The Electricity Journal 31: 9-13.

Satchwell, A., M. A. Piette, A. Khandekar, J. Granderson, N. Mims Frick, R. Hledik, A. Faruqui, L. Lam, S. Ross, J. Cohen, K. Wang, D. Urigwe, D. Delurey, M. Neukomm and D. Nemtzow (2021). A National Roadmap for Grid-Interactive Efficient Buildings, U.S. Department of Energy.

Say, K., W.-P. Schill and M. B. John (2020). "Degrees of displacement: The impact of household PV battery prosumage on utility generation and storage." Applied Energy 276: 115466.

Sayed, K. and H. Gabbar (2018). Building Energy Management Systems (BEMS). Energy Conservation in Residential, Commercial, and Industrial Facilities. H. A. Gabbar, Wiley-IEEE Press. 
Seel, J., A. Mills, C. Warner, B. Paulos and R. Wiser (2020). Impacts of High Variable Renewable Energy Futures on Electric Sector Decision-Making: Demand-Side Effects. Berkeley, CA, Lawrence Berkeley National Laboratory.

SEIA (2018). Solar Energy \& Commercial Real Estate (CRE), Solar Energy Industries Association.

Sigrin, B., T. Dietz, A. Henry, A. Ingle, L. Lutzenhiser, M. Moezzi, S. Spielman, P. Stern, A. Todd, J. Tong and K. Wolske (2017). Understanding the Evolution of Customer Motivations and Adoption Barriers in Residential Solar Markets: Survey Data. N. R. E. Laboratory.

Smil, V. (2017). Energy and Civilization: A History. Cambridge, MA, The MIT Press.

Sofos, M., J. Langevin, M. Deru, E. Gupta, K. Benne, D. Blum, T. Bohn, R. Fares, N. Fernandez, G. Fink, S. Frank, J. Gerbi, J. Granderson, D. Hoffmeyer, T. Hong, A. Jiron, S. Johnson, S. Katipamula, T. Kuruganti, W. Livingood, R. Muehleisen, M. Keuhomm, V. Nubbe, P. Phelan, M. A. Piette, J. L. Reyna, A. Roth, A. Satre-Meloy, M. Specian, D. Vrabie, M. Wetter and S. Widergren (2020). Innovations in Sensors and Controls for Building Energy Management: Research and Development Opportunities Report for Emerging Technologies, U.S. Department of Energy.

Specian, M., C. Cohn and D. York (2021). Demand-Side Solutions to Winter Peaks and Constraints, ACEEE.

Spector, J. (2020). 10 Victories for Virtual Power Plants in 2020. Greentech Media.

Steinberg, D., D. Bielen, J. Eichman, K. Eurek, J. Logan, T. Mai, C. McMillan, A. Parker, L. Vimmerstedt and E. Wilson (2017). Exploring U.S. Energy Use and Greenhouse Gas Emissions in Scenarios with Widespread Electrification and Power Sector Decarbonization, National Renewable Energy Laboratory.

Stoll, B., E. Buechler and E. Hale (2017). "The value of demand response in Florida." The Electricity Journal 30: 57-64.

Subarrao, K., J. Fuller, K. Karanjit, R. Pratt, S. Widergreen and D. Chassin (2013). Transactive Control and Coodination of Distributed Assets for Ancillary Services, Pacific Northwest National Laboratory.

Sun, Y., P. Jadun, B. Nelson, M. Muratori, C. Murphy, J. Logan and T. Mai (2020). Electrification Futures Study: Methodological Approaches for Assessing Long-Term Power System Impacts of End-Use Electrification. Golden, CO, National Renewable Energy Laboratory.

Sung, J., I. Hamilton, G. Kamiya, K. Lane, L. Lopez, Y. Moschauer, M. Oppermann and H. Salamanca (2020). Energy Efficiency 2020. Paris, International Energy Agency.

Surampudy, M., B. Chew, M. Keller and T. Gibson (2019). 2019 Utility Demand Response Market Snapshot, Smart Electric Power Alliance. 
Sussman, R. and R. Gifford (2014). The Pscyhology of Climate Change. Environmental Pscyhology: Principles and Practice. R. Gifford, Optimal Books. 5.

Teplin, C., M. Dyson, A. Engel and G. Glazer (2019). The Growing Market for Clean Energy Portfolios: Economic Opportunities for a Shift from New Gas-Fired Generation to Clean Energy Across the United States. Boulder, CO, Rocky Mountain Institute.

U.S. Census (2020). Quarterly Residential Vacancies and Homeownership, Third Quarter 2020, U.S. Census Bureau.

Urban Green (2020). Going Electric: Retrofitting NYC'S Multifamily Buildings. New York, NY, Urban Green Council.

Van Der Stelt, S., T. AlSkaif and W. Van Sark (2018). "Techno-economic analysis of household and community energy storage for residential prosumers with smart appliances." Applied Energy 209: $266-276$

Wang, N. N. (2018). "Transactive control for connected homes and neighbourhoods." Nature Energy 3(11): 907-909.

Wanger, T. C. (2011). "The Lithium future-resources, recycling, and the environment." Conservation Letters 4(3): 202-206.

Welton, S. and J. Eisen (2019). "Clean Energy Justice: Charting an Emerging Agenda." Harvard Environmental Law Review 43: 307-371.

White, L. and N. Sintov (2020). "Health and financial impacts of demand-side response measures differ across sociodemopgrahic groups." Nature Energy 5(1): 50-60.

Wilson, J. D., M. O'Boyle, R. Lehr and M. Detsky (2020). Making the Most of the Power Plant Market: Best Practices ofr All-Source Electric Generation Procurement, Energy Innovation.

Wolske, K., K. Gillingham and W. Schultz (2020). "Peer influence on household energy behaviours." Nature Energy 5: 202-212.

Wolske, K., P. Stern and T. Dietz (2017). "Explaining interest in adopting residential solar photovoltaic systems in the United States: Toward an integration of behavioral theories." Energy Research and Social Science 25: 134-151. 


\section{Appendix. Modeling Notes}

DPV Projections

Households and building owners adopt DPV for a variety of reasons. The complexity of these decisions notwithstanding, we know that most adopters are at least partially motivated to adopt DPV as a way to reduce electricity costs (Sigrin, Dietz et al. 2017). As a result, we can project potential DPV adoption based on projected costs for DPV systems relative to grid electricity costs. We used NREL's Distributed Generation Market Demand (dGen) model to project potential DPV deployment. dGen is an agent-based model for simulating customer adoption of clean energy technologies (see https://www.nrel.gov/analysis/dgen/). We projected DPV adoption under three representative rate structure scenarios: (1) a business-as-usual case (mostly flat volumetric rates), (2) a scenario where all customers are switched to time-of-use rates based on rate structures used by Pacific Gas \& Electric in California, and (3) a scenario where all customers are switched to demand charge rate structures based on structures used by Arizona Public Service. Finally, we estimated ranges of potential deployment based on (1) a standard DPV price reduction case, where total DPV capital costs decline by $68 \%$ from 2020 to 2050, and (2) a low DPV price reduction case, where costs decline by $75 \%$. The results of these projections are illustrated in Figure 8.

\section{Building Energy System Orchestration}

We modeled the value of building energy orchestration using the URBANopt and REopt modeling platforms. URBANopt is a platform for modeling high-performance buildings and energy systems (see https://www.nrel.gov/buildings/urbanopt.html). REopt is a techno-economic decision support platform to identify economically optimal combinations of distributed clean energy technologies (see https://reopt.nrel.gov/). We used URBANopt to simulate building load profiles for a representative mall and hotel. After simulating a scenario in URBANopt, we determined the optimal mix and sizing of DPV and battery systems for that scenario using REopt. The scenarios varied along three dimensions. First, the DPV and battery systems in the two buildings could be optimized separately (unit optimization) or together (orchestration). Second, building energy use could be modeled based on standard- or high-efficiency buildings. Third, systems could be modeled based on energy-heavy $(\$ / \mathrm{kWh})$ or demand charge-heavy $(\$ / \mathrm{kW})$ rate structures. The results presented in Figure 11 are based on the energy chargeheavy scenario. 